\title{
Overview of Ultrasonic Assisted Manufacturing Multifunctional Carbon Nanotube Nanopaper Based Polymer Nanocomposites
}

\author{
Dan Zhang ${ }^{1}$, Jingyao $\operatorname{Sun}^{2, *}$, L. James Lee ${ }^{3}$ and Jose M. Castro ${ }^{1, *}$
}

\begin{abstract}
Carbon nanotube (CNT) nanopaper (NP) has become a promising platform to fabricate light weight multifunctional polymer nanocompos- ites, because of superior properties of CNTs including low density, high strength and modulus, high electrical and thermal conductivities, etc. However, the low permeability of CNT NP $\left(10^{-17}\right.$ to $\left.10^{-19} \mathrm{~m}^{2}\right) \mathrm{makes}^{\mathrm{k}}$ it difficult to be impregnated by resin to fabricate nanocomposites via conventional approaches, such as resin transfer molding and hot melt compression molding. The resin infiltration time is usually more than one hour, and uniform resin impregnation is difficult to be achieved. Additionally, solvent is required to decrease the resin viscosity to facilitate the resin infiltration. All these make the process environmentally unfriendly and significantly limit the industrial applications of NP/polymer nanocomposites. Therefore, a novel ultrasonic assisted infiltration technology is developed to fabricate the NP/polymer nanocomposites with a uniform nanoparticle dispersion and high loadings (>20 wt\%). The high frequency $(20 \mathrm{kHz})$ ultrasonic vibration al- lows to effectively infiltrate various types of resins, including thermoplastic polyurethane (TPU), thermoset epoxy (EP), and elastomer polydimethylsiloxane (PDMS) into CNT NP within a few seconds, followed by polymerization. A systematic review was conducted to re- port on the $\mathrm{NP} /$ polymer nanocomposite fabrication process and the properties of the nanocomposites together with their detailed exempla- ry applications.
\end{abstract}

Keywords: Polymer nanocomposites; Carbon nanotube; Nanopaper; Ultrasonic infiltration Received: 20 January 2020; Accepted: 4 March 2020

Article type: Review article

\section{Introduction}

After being invented in 1991, carbon nanotube (CNT) has been used to reinforce a variety of polymers in order to fabricate polymer nanocomposites with different functionalities. As one of the carbon based nanomaterials, CNT has several outstanding properties including low density, high aspect ratio, high strength, high electrical and thermal conductivities, which make it an excellent reinforcement for polymer matrices. ${ }^{[1-9]}$ Numerous journal articles and patents related to CNT reinforced polymer nanocomposites have been documented in the last two decades. As the price of CNT continues to decrease from several hundred dollars to less

\footnotetext{
${ }^{I}$ Department of Integrated Systems Engineering, The Ohio State University, 1971 Neil Avenue, Columbus, OH 43210, USA

${ }^{2}$ College of Mechanical and Electrical Engineering, Beijing University of Chemical Technology, Beijing 100029, China

${ }^{3}$ Department of Chemical and Biomolecular Engineering, The Ohio State University, 151 West Woodruff Avenue, Columbus, OH 43210, USA

E-mail: sunjingyao@mail.buct.edu.cn (J. Sun); castro.38@osu.edu (J.M. Castro)
}

than a hundred per kilogram, more and more industrial applications in aerospace, automotive and sporting goods markets have been developed.

Conventional methods such as solution mixing and melt blending have been used to disperse CNT into polymeric matrices. However, it is challenging to obtain nanocomposites with a uniform nanoparticle dispersion and high loadings ( $>10 \mathrm{wt} \%$ ) because, for example, the viscosity increases more than 100 times after adding just $1 \mathrm{wt} \%$ CNT into the matrix due to its large specific surface area. ${ }^{[10,11]}$ If the dispersion is poor, the CNTs aggregate and adversely affect the mechanical properties of the nanocomposite. ${ }^{[7]}$

Rather than dispersing the CNTs into the polymeric matrix, starting with a pre-made nanopaper (NP) and then infiltrating the polymeric matrix into the NP is an effective way to obtain high loading, well dispersed CNT nanocomposites with improved properties. Thus, the CNT NP is used as an excellent platform to fabricate light weight multifunctional 
nanocomposites due to the superior properties of the CNTs. CNT NP is a porous film with a thickness ranging from 20 to several hundred microns, generally fabricated by chemical vapor deposition (CVD), ${ }^{[12-15]}$ or dispersion and filtration, ${ }^{[8,16-18]}$ or hydroentangling ${ }^{[19]}$ and spinning. ${ }^{[20]}$ The CVD approach could produce aligned NPs with a higher strength and electrical conductivities, but the cost of production is also higher. Thus, the dispersion and filtration method is much more feasible for mass production and commercialization at a lower cost. Besides working as a reinforcement of nanocomposites, individual CNT NP could be used for strain sensor and actuator, ${ }^{[21-24]}$ gas separation membrane, ${ }^{[25]}$ gas and vapor detector, ${ }^{[26]}$ and deicing. ${ }^{[27]}$

Resin transfer molding, solvent casting, and compression molding have been used to infiltrate different types of polymeric matrices into the NP to fabricate nanocomposites. The achieved $\mathrm{NP} /$ polymer nanocomposites displayed significantly improved properties such as mechanical strength and Young's modulus, electricity conductivity, electromagnetic interference (EMI) shielding, thermal conductivity, and thermal stability, etc. ${ }^{[28-37]}$ However, the permeability of CNT NP ranges from $10^{-17}$ to $10^{-19} \mathrm{~m}^{2}{ }^{[16,38,39]}$ which is several order of magnitude smaller than the glass fiber or carbon fiber preform $\left(10^{-19}\right.$ to $10^{-12} \mathrm{~m}^{2}$ ), leading to a longer resin infiltration time and limiting the industrial applications of CNT NP for making nanocomposites. The novel ultrasonic process is developed to greatly decrease the infiltration time and thus improves the potential for industrial applications.

The benefits of novel ultrasonic approach have been demonstrated by different polymer matrices such as epoxy, polyurethane (PU), and polydimethylsiloxane (PDMS). The thermoset epoxy, thermoplastic PU, and elastomer PDMS represent three major classes of polymers with significant differences in viscosity and end-use properties. The viscosity of the resin ranges from 0.1 to $10 \mathrm{~Pa} \cdot \mathrm{s}$ at their processing temperatures. For example, the viscosity of epoxy resin is $0.17 \mathrm{~Pa} \cdot \mathrm{s}$ at $90^{\circ} \mathrm{C}$. For thermoplastic polyurethane (TPU) resin, it is $0.12 \mathrm{~Pa} \cdot \mathrm{s}$ at $70^{\circ} \mathrm{C}$. For PDMS resin, it is 10

$\mathrm{Pa} \cdot \mathrm{s}$ at room temperature. These three types of NP nanocomposites have different end-use properties, thus a variety of applications can be envisioned. The solventless epoxy was selected to study the process parameters of ultrasonic infiltration process because of its wide processing window. The CNT NP/polymer nanocomposites were evaluated as coatings for glass fiber reinforced polymer composite (GFRP) providing an improved abrasion resistance for wind energy and automotive industries. ${ }^{[17,40,41]}$ The TPU based NP nanocomposites can be processed by injection and extrusion molding. ${ }^{[41]}$ Because of their good biocompatibility and ductility, the PDMS based NP nanocomposites can be used as strain sensors to monitor the movement of human body parts, such as neck, arm, wrist, and leg, etc. ${ }^{[42]}$

In this paper, novel ultrasonic assisted resin infiltration method was discussed with its utilization to prepare CNT
NP nanocomposites with a uniform resin impregnation at an industrially attractive processing rate. Major characteristics were disclosed including the reduced infiltration time (4 seconds compared to more than 30 minutes for the resin transfer molding). The microstructure, morphology, mechanical properties, abrasion resistance, electromagnetic interference (EMI) shielding, strain dependent electrical response, and process flexibility of the NP/polymer nanocomposites were reviewed as well.

\section{Nanocomposites Processing}

\subsection{Solution and melt compounding}

It is a major challenge to uniformly disperse CNT into a polymer matrix and to obtain high loading $(>10 \mathrm{wt} \%)$ using conventional methods such as extrusion and shear mixing because of the large viscosity increase resulting from the large specific surface area of CNTs. ${ }^{[10]}$

Twin screw extrusion has been used to compound polypropylene (PP), polyethylene (PE), polystyrene (PS), polyethylene terephthalate (PET), and PU with CNT from 1 to $10 \mathrm{wt} \%$, and the nanocomposites exhibit improved Young's modulus, tensile strength, electrical and thermal conductivities. ${ }^{[43-52]}$ Besides extrusion, CNT has been dispersed in epoxy or TPU monomers via shear mixing and ultra-sonication, followed by polymerization, and the nanocomposites demonstrated improved mechanical, electrical and thermal properties. ${ }^{[53-59]}$

Similarly, solution mixing method has been used to disperse CNTs in epoxy to fabricate nanocomposites using solvents such as ethanol, acetone or N, N Dimethylformamide (DMF), etc. The process includes dispersing CNTs in solvent by sonication or shear mixing, then adding epoxy monomer and curing agent separately followed by degassing and curing, which takes several hours in total. ${ }^{[60-62]}$ The required organic solvents in these conventional compounding approaches not only were environmentally unfriendly, but also significantly increased the processing time due to the removal of solvent. ${ }^{[2,60,61]}$ The trapped solvent could reduce the mechanical properties of the nanocomposites. ${ }^{[63]}$ All of these issues significantly decrease the potential of commercialization of nanocomposites.

\subsection{Nanopaper and resin transfer molding}

An effective way to obtain high loadings and better dispersion is to start with a nanopaper and then to infiltrate the polymer into the porous structure. Nanomaterials such as CNT, carbon nanofiber (CNF), and cellulose nanofiber can be used to fabricate nanopapers using the dispersion and filtration method. First, the nanomaterials need be dispersed in water with the aid of a surfactant using a probe sonicator to reach uniform dispersion. Surfactant such as sodium dodecyl sulfate (SDS) has both hydrophobic and hydrophilic functional groups to interact with the nanoparticle and water molecule, respectively to achieve a good dispersion. The 
concentration of nanoparticle is usually maintained lower than $0.2 \mathrm{wt} \%$. The aqueous CNT (or CNF) dispersion is then filtered through a polytetrafluoroethylene (PTFE) membrane laid on a porous metal support in a home-made funnel (10 " $\times 12$ ") to form the NP. The SDS was then washed away by ethanol and distilled water. Finally, the nanopaper was peeled from the membrane and vacuum dried to remove moisture. ${ }^{[17,41]}$ The process is shown schematically in Fig. 1.

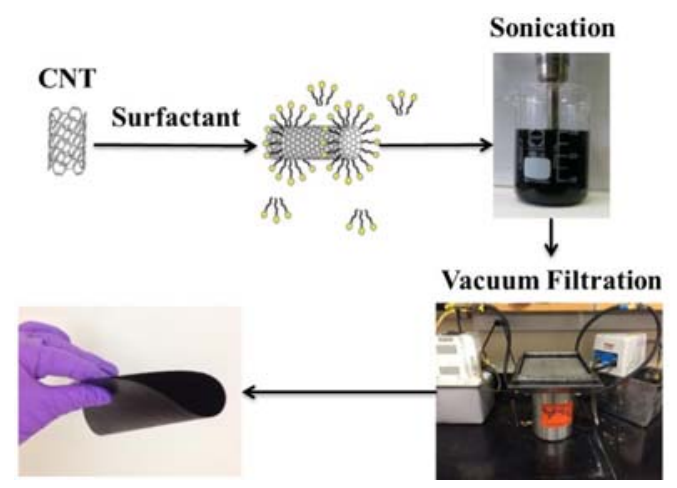

Fig. 1 CNT nanopaper fabrication process. Reproduced with permission.

The fabricated NP is a thin film with the thicknesses ranging from 20 to several hundred $\mu \mathrm{m}$. Very few agglomerations of CNF or CNT from the SEM studies of the nanopapers indicated that the surfactant effectively dispersed the nanoparticles in water. The nanofibers or nanotubes were randomly entangled in the NP, and held by van der Waals forces. The pore sizes of CNT NP are much smaller than CNF NP because the CNT has much smaller dimensions compared to CNF. The porosity of CNF NP is $80 \%$, higher than CNT NP (72\%). The tensile strength of CNF NP is 1 $\mathrm{MPa}$, much lower than CNT NP (4.8 MPa). Detailed information of the nanomaterials are stated as: CNF with a diameter of $100 \mathrm{~nm}$ and a length of 50 200 $\mu \mathrm{m}$; multi-wall CNT with an inside diameter of $3 \sim 5 \mathrm{~nm}$, outer diameter of $8 \sim 15 \mathrm{~nm}$ and an length of $3 \sim 12 \mu \mathrm{m}$; and single-wall CNT with a diameter of $1.8 \pm 0.4 \mathrm{~nm}$ and a length of $>5 \mu \mathrm{m}$.

CNF NP could be placed on the top of a glass fiber preform to fabricate nanocomposites using the vacuum assisted resin transfer molding (VARTM) for surface protection of products such as wind turbine or sporting goods. The sketch of the material layup and the VARTM process is shown in Fig. 2. A systematic study on the permeability of CNF NP was conducted to investigate the resin infiltration into the NP. ${ }^{[64]}$ Improvements in mechanical properties and sand erosion resistance were achieved. ${ }^{[16]}$

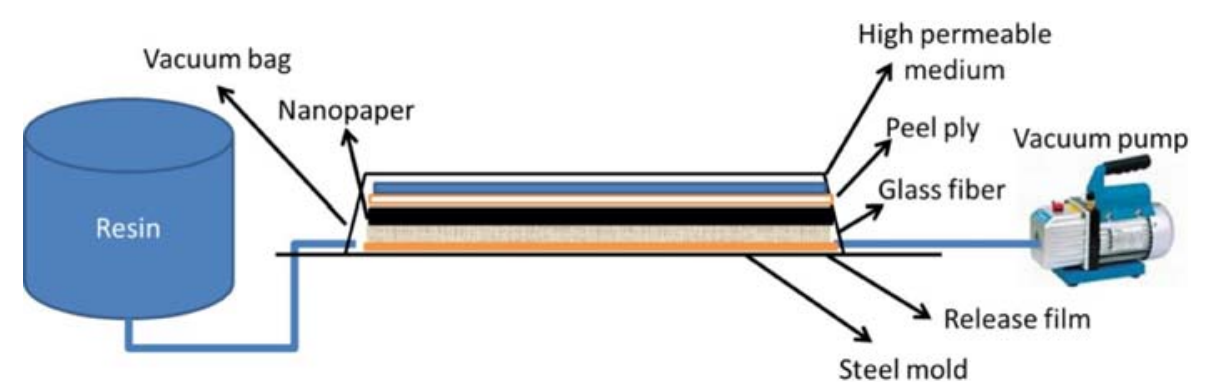

Fig. 2 Vacuum assisted resin transfer (VART) molding process. Reproduced with permission. ${ }^{[16]}$ (Copyright $(2017$ Wiley Periodicals, Inc.)

Compared to CNF, CNT with a smaller diameter and larger aspect ratios could provide the NP with a higher mechanical strength and electrical conductivity, which further improve the surface protection of polymer composite substrates. However, a lower permeability of CNT NP $\left(10^{-17}\right.$ to $\left.10^{-19} \mathrm{~m}^{2}\right)$ compared to CNF NP $\left(10^{-15} \mathrm{~m}^{2}\right)$ hinders the polymer impregnation. Therefore, it is difficult to achieve NP nanocomposites with a uniform resin impregnation via VARTM method. The long processing time ( $>1 \mathrm{hr}$ ) significantly limits the process flexibility and potential industrial scale up.

\section{Ultrasonic processing of CNT nanopaper nanocomposites}

The innovative ultrasonic infiltration method can effectively fabricate CNT NP nanocomposites with a high CNT loading $(>20 \mathrm{wt} \%)$ at a fast infiltration rate $\left(4\right.$ seconds). ${ }^{[17]}$ The experimental setup for the ultrasonic infiltration process (a Branson 921 ultrasonic welding unit) is shown in Fig. 3. A stack of materials was placed inside the mold. The Teflon sheet was used to protect the integrity of CNT NP during the strong ultrasonic infiltration. Polymer matrix (e. g. epoxy,
TPU, PDMS, etc.,) was degassed, then poured on the top of CNT NP. The ultrasonic horn moved down and contacted the material stack, and then the ultrasonic wave was generated to impregnate the resin into the NP, fabricating the $\mathrm{NP} /$ polymer prepreg. Impregnation was followed by curing to manufacture the nanocomposites.

This novel ultrasonic process combines the ultrasonic cavitation, high-frequency vibration, and microstreaming effects to enhance the penetration of resin into nanopores of the NP. The mechanisms for ultrasonic impregnation of polymer into porous media like fiberglass, carbon fiber preform, and CNT NP are due to physical and chemical effects. High intensity ultrasonic energy can produce forceful agitations in the liquid mediums ${ }^{[64]}$ accompanied by a reduction in the effective viscosity, ${ }^{[65]}$ which enhances the impregnation of porous media.

A systematic study of process parameters was carried out to understand the process windows for this novel process. The frequency of ultrasonic wave used was $20 \mathrm{kHz}$. The process parameters including ultrasound time ( 2 or $6 \mathrm{~s}$ ), ultrasound amplitude $(25$ or $39 \mu \mathrm{m})$, pressure $(40$ or $80 \mathrm{psi})$ 
and mold temperature $\left(50\right.$ to $\left.90^{\circ} \mathrm{C}\right)$ were used during the infiltration of resin into the CNT NP. Besides the process parameters, NPs with different compositions (different ratios of multi wall CNT (MWNT) to single wall CNT (SWNT) were also studied. After ultrasonic infiltration, the CNT $\mathrm{NP} /$ polymer prepregs were put into the rollers $\left(90^{\circ} \mathrm{C}\right)$ to remove the surface resin. The prepregs were cured following the procedures provided by the resin manufacturers. The NP swelled from $50 \mu \mathrm{m}$ thick to approximately 95 to $100 \mu \mathrm{m}$ thick after resin impregnation measured by digital micrometer. A block diagram of the CNT NP/polymer nanocomposite manufacturing process is shown in Fig. 4.

The resin infiltration of this novel ultrasonic process was significantly decreased to 4 seconds compared to longer than 30 minutes by the traditional RTM process. This significantly decreased the manufacturing cost. Besides, no required solvent made it environmentally friendly. Therefore, it is possible to build a continuous ultrasonic infiltration process to scale up the $\mathrm{NP} /$ polymer nanocomposite fabrication for commercialization.
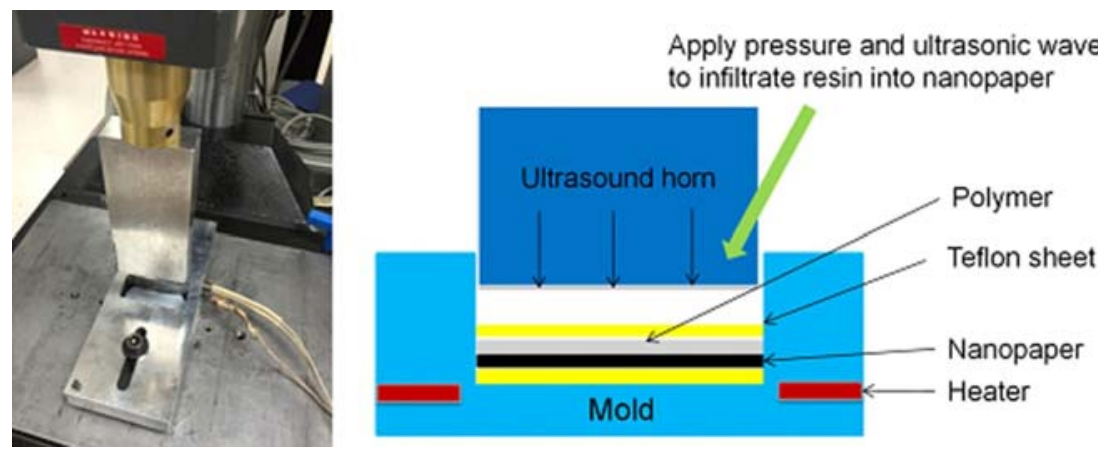

Fig. 3 Ultrasonic infiltration process. (Modified from ref. [17])

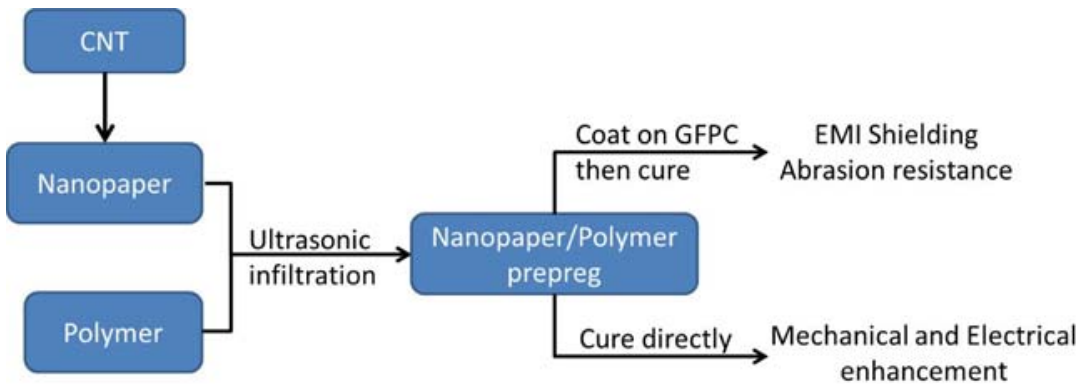

Fig. 4 Nanopaper nanocomposite fabrication process. Reproduced with permission.[17] (Copyright (C) 2018 Elsevier Ltd.)

\section{Nanopaper properties}

\subsection{Physical properties}

Both MWNT and SWNT can be used to fabricate NP. The composition of the NP determines its micro-structures, and thus affects its macroscopic properties. SWNT has a higher aspect ratio, strength and modulus compared to MWNT. Three NP compositions, i. e. 1) $100 \%$ MWNT, 2) $60.6 \%$ SWNT and 39.4\% MWNT, and 3) $100 \%$ SWNT were selected to study their properties by the max-min optimization method. ${ }^{[17,67]}$

For MWNT NP, the observed individual NTs revealed very few CNT. ${ }^{[17]}$ The MWNTs were effectively dispersed by the surfactant SDS at a concentration of $0.2 \mathrm{wt} \%$. The NTs were randomly entangled in MWNT NP, and held by van der walls forces, which allowed the porous area to be filled by polymer matrix. The nanotube agglomerations were observed to increase in $60.6 \%$ SWNT NP and $100 \%$ SWNT NP compared to MWNT NP. This was because of the increase of SWNT $w t \%$ in the NP. It was more difficult to disperse SWNTs because of the higher specific surface area and larger aspect ratio, thus more nanotube bundles were formed. The increase of nanotube agglomerations in the NP decreased its permeability. The permeability of MWNT NP was $1.3 \times 10^{-17} \mathrm{~m}^{2}$, and was decreased to $2.8 \times$ $10^{-18} \mathrm{~m}^{2}$ for $60.6 \%$ SWNT NP, and $3.4 \times 10^{-19} \mathrm{~m}^{2}$ for $100 \%$ SWNT NP. The density of these three NPs was $0.55,0.74$ and $0.90 \mathrm{~g} / \mathrm{cm}^{3}$.

The tensile test revealed that the tensile strength of MWNT NP was $4.8 \mathrm{MPa}$, and increased to 27.8 and 66.5 MPa for $60 \%$ SWNT NP and $100 \%$ SWNT NP, respectively. The much higher tensile strengths of SWNT NPs compared to MWNT NP were due to more nanotube entanglements. All NPs are brittle with the strain at break lower than 5\%. It can be concluded that the increased SWNT wt $\%$ in NP led to an increase of mechanical property, but a decrease of permeability, which adversely affected the resin infiltration and nanocomposite fabrication.

In order to balance the mechanical property and permeability, hybrid NP which includes $10 \%$ SWNT and $90 \%$ MWNT (i. e. $10 \%$ SWNT NP) was fabricated. Its tensile strength was $9.8 \mathrm{MPa}$, which was a $104 \%$ increase compared to MWNT NP. SEM microstructure studies 
revealed that most NTs were uniformly distributed, although some bundles were formed in the $10 \%$ SWNT NP compared to the MWNT NP. The permeability was $8.1 \times 10^{-18} \mathrm{~m}^{2}$. The NPs with a higher SWNT\%, for example, $>10 \%$, could form more nanotube bundles inside, which adversely affected the resin impregnation. ${ }^{[41]}$ Thus, $10 \%$ SWNT NP was chosen to fabricate nanocomposites.

\subsection{Electromagnetic interference (EMI) shielding property} EMI shielding is a key property to protect the electronic devices on the civil and military aircrafts, and automobile. Because of the high electrical conductivity, high aspect ratio, and low density, and corrosion resistance, the CNT NP polymer nanocomposites have high potential to replace traditional metallic EMI shielding products.

The EMI shielding effectiveness (SE) of a material is defined as $S E(\mathrm{~dB})=-10 \log \left(P_{t} / P_{0}\right)$, where $P_{t}$ and $P_{0}$ are the transmitted and incident electromagnetic power, respectively. The EMI SE values of nanocomposite samples and control sample were measured by a N5230A PNA-L network analyzer (Agilent Technologies) according to ASTM standard D4935. The EMI SE of the NPs together with carbon fiber preform (control group) is shown in Fig. 5. The frequency ranges from $30 \mathrm{MHz}$ to $1.5 \mathrm{GHz}$. The $52 \mu \mathrm{m}$ thick MWNT NP reached an average SE of $29 \mathrm{~dB}$. By adding $10 \%$ SWNT, the average EMI SE of NP was increased to $41 \mathrm{~dB}$. The SE was increased to $51 \mathrm{~dB}$ for $60 \%$ SWNP, and $57 \mathrm{~dB}$ for $100 \%$ SWNT NP, higher than the commercial carbon fiber preform $(55 \mathrm{~dB})$ with a thickness

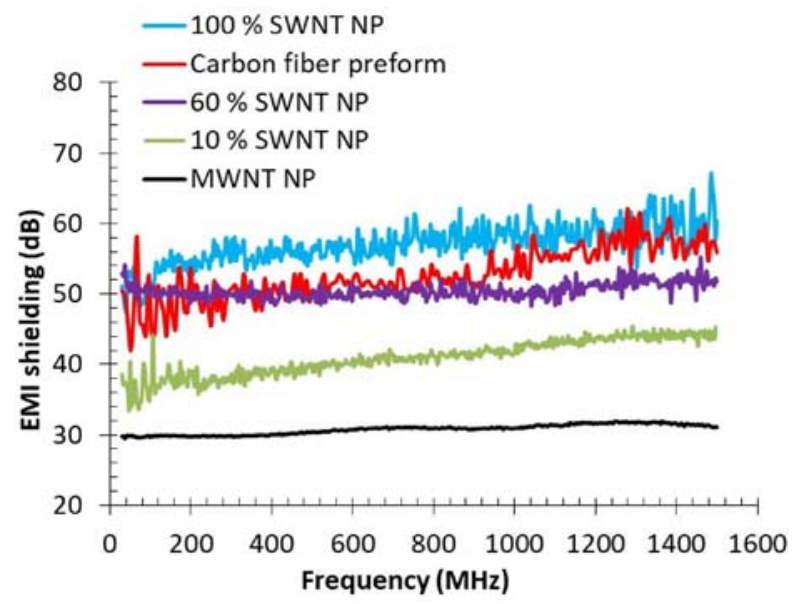

Fig. 5 EMI shielding of nanopapers. (Modified from ref. [41])

of $258 \mu \mathrm{m}$. The carbon fiber preform was $2 \times 2$ Twill Weave purchased from Fibre Glast Developments Corporation, Brookville, $\mathrm{OH}$. The increased SE was because of a higher electrical conductivity of the SWNTs and a higher aspect ratio compared to MWNT, which improved the absorption of electromagnetic waves. Absorption accounted for $99 \%$ of the SE of the NP, and reflection accounted for $1 \%$. The multi reflection was negligible. The sheet electrical resistance of MWNT NP was $6.2 \Omega / \mathrm{sq}$, and was decreased to 1.2 and $0.051 \Omega / \mathrm{sq}$ for $10 \%$ SWNT NP and $100 \%$ SWNT NP, respectively.

\section{The properties of the nanocomposites}

The powerful ultrasonic vibration allows to effectively infiltrate various types of monomers followed by polymerization, including thermoset EP, TPU, and elastomer PDMS, into the NP within 4 seconds. Based on polymer matrix and NP, different performance enhancements and applications of the nanocomposites were demonstrated. The mechanical properties and micro-structures of all three $\mathrm{NP} /$ polymer nanocomposites were investigated. The significantly improved abrasion resistance of the nanocomposites was studied, and potential applications were wind energy and automotive industries. Because of TPU's high ductility and process flexibility, i.e. being melted and attached on different substrates, the EMI shielding of its CNT NP nanocomposites was demonstrated towards aerospace applications. Because of PDMS's high ductility and bio-compatibility, the strain sensing property of CNT NP/PDMS nanocomposites and its application on human wearable device were demonstrated.

\subsection{Microstructure and mechanical property}

The mechanical properties of the CNT NP/polymer nanocomposites were improved significantly compared to both the polymer matrix and the CNT NP, because of uniform resin impregnation into the CNT NP. The viscosity of each matrix resin (uncured) was measured at its infiltration temperature. The viscosity of EP resin was 0.17 $\mathrm{Pa} \cdot \mathrm{s}$ at $90{ }^{\circ} \mathrm{C}$. The viscosity of TPU resin was $0.12 \mathrm{~Pa} \cdot \mathrm{s}$ at $70{ }^{\circ} \mathrm{C}$. The viscosity of PDMS resin was $10 \mathrm{~Pa} \cdot \mathrm{s}$ at room temperature. EP was selected because of its long process window, i. e. 5 hours at $90{ }^{\circ} \mathrm{C}$, rather than TPU (20 minutes at $70{ }^{\circ} \mathrm{C}$ ) and PDMS (30 minutes at room temperature). Micron injection molding of CNT NP/TPU and CNT NP/PDMS was demonstrated with a process flexibility.

\subsubsection{CNT NP/Epoxy nanocomposites}

5.1.1.1 Ultrasonic process study

The process parameters of the ultrasonic infiltration process were studied in fabricating MWNT NP/EP nanocomposites. The used epoxy was EPON 828 (Hexion Chemicals, Columbus, $\mathrm{OH})$. The curing agent was 4, 4'-diaminodiphenylsulfone. It was a solventless, specially designed for hot melt process to fabricate prepreg composites. The important process parameters include ultrasonic amplitude, ultrasonic time (i. e. infiltration time), pressure and mold temperature. A two-level full factorial design of experiment (DOE), i.e. ultrasonic amplitude 25 or $39 \mu \mathrm{m}$, ultrasonic time 2 or $6 \mathrm{~s}$, was first conducted to determine their effects on the resin impregnation during the ultrasonic process, and the mechanical properties of the fabricated nanocomposites. The pressure was maintained at $40 \mathrm{psi}$, and the mold temperature was at $90^{\circ} \mathrm{C}$ (recommended temperature by the manufacturer).

Thermalgravimetric analysis (TGA) studies revealed 
the overlapping TGA curves of nanocomposites, indicating that EP impregnation into the MWNT NP was not significantly affected by ultrasonic amplitude or ultrasonic time, when the ultrasonic time was more than $2 \mathrm{~s}$. The remaining $\mathrm{wt} \%$ of MWNT NP and pure EP under $700^{\circ} \mathrm{C}$ were $98.9 \%$ and $7.5 \%$ respectively according to TGA results. Based on Eqs. (1) and (2), MWNT wt $\%$ in the nanocomposites was $30.5 \%$ regardless of infiltration conditions.

$$
\begin{gathered}
W_{N P}+R_{N P}+W_{\text {epoxy }} R_{\text {epoxy }}=1 \\
W_{N P}+W_{\text {epoxy }}=1
\end{gathered}
$$

where $W_{N P}$ and $W_{\text {epoxy }}$ are the weight percentage of the NP and epoxy in the nanocomposite, while $R_{N P}$ and $R_{\text {epoxy }}$ are the residual weight of the NP and EP, respectively.

For the MWNT NP/epoxy nanocomposites processed under the condition with an ultrasonic amplitude of $25 \mu \mathrm{m}$, the tensile strength reached the highest (105MPa), a $27.3 \%$ improvement compared to EP (82.5MPa), and 21 times improvement compared to MWNT NP (4.8MPa). As the amplitude increased from 25 to $39 \mu \mathrm{m}$, the tensile strength was decreased from 105 to $87 \mathrm{MPa}$, regardless of the ultrasonic time ( 2 or $6 \mathrm{~s})$. The possible reason of the decrease in tensile strength is a higher impact onto the NP when applying a higher amplitude for resin impregnation.

Pressure is another important factor in the flow through porous media, i. e. resin infiltration into NP. Two pressure values (40 or $80 \mathrm{psi}$ ) were used to infiltrate EP into MWNT NP. Ultrasonic time (2 or $6 \mathrm{~s}$ ) was also used making it a two-level full factorial DOE. Amplitude $25 \mu \mathrm{m}$ was used because of its positive effect on the nanocomposite's tensile strength compared to the amplitude of $39 \mu \mathrm{m}$. The tensile strength data indicated that a pressure of $80 \mathrm{psi}$ led to a significantly lower tensile strength (84MPa) compared to that of $40 \mathrm{psi}(105 \mathrm{MPa})$ regardless of the ultrasonic time (2 or $6 \mathrm{~s})$. This might be because a higher pressure during the impregnation process damages the MWNT NP. From the results above, it can be concluded that a lower amplitude and a lower pressure result in a higher nanocomposite tensile strength.

The resin viscosity is an important factor in the resin impregnation of a nano porous network. SEM studies revealed that the MWNT NP had a pore size approximately less than $100 \mathrm{~nm}$. The viscosity lower than $0.5 \mathrm{~Pa} \cdot \mathrm{s}$ was reported to be needed to successfully impregnate the NPs. ${ }^{[67,68]}$ To study the effect of viscosity on ultrasonic impregnation of EP into MWNT NP, the mold temperature was varied at 50,70 and $90^{\circ} \mathrm{C}$ resulting in the EP resin viscosity values of 9.6, 0.8, and $0.166 \mathrm{~Pa} \cdot \mathrm{s}$, respectively. The ultrasonic time was $2 \mathrm{~s}$, the pressure was $40 \mathrm{psi}$, and the amplitude was 25 $\mu \mathrm{m}$.

The tensile fracture surfaces of the MWNT NP/EP nanocomposites fabricated at three process conditions were studied by SEM. The pores in the NPs were observed to be filled with EP resin, together with observed very few CNT aggregates or voids. This indicates that infiltration is homogeneous in these three nanocomposites regardless of resin viscosity. Many observed pull-out nanotubes explained the ineffective load transfer between EP and nanotube, which limited the tensile strength improvement from CNT reinforcement. The viscosity insensitivity in the ultrasonic resin impregnation of MWNT NP might be caused by the effect of intense ultrasonic vibration. The mechanisms for ultrasonic impregnation of polymer into porous CNT NP are due to physical and chemical effects. High intensity ultrasonic energy can produce forceful agitation in liquid mediums ${ }^{[65]}$ accompanied by a reduction in the effective viscosity ${ }^{[69]}$ which enhance the impregnation of porous media.

For the MWNT NP/EP nanocomposite, the consistent electrical resistance distribution ( 35 to $40 \mathrm{Ohm}$ ) along the thickness direction ( 0 to $100 \mu \mathrm{m}$ ) confirmed a uniform resin impregnation along the thickness direction. Due to the rubbery nature of CNT NP/TPU and CNT NP/PDMS nanocomposites, their samples could not be grinded, thus this analysis was not done for these two types of nanocomposites.

\subsubsection{Nanopaper composition for nanocomposites}

Besides the process parameters, the composition of the NP by changing the SWNT $\mathrm{wt} \%$ and MWNT $\mathrm{wt}^{\mathrm{t}} \%$ is also important to the resin impregnation and performance of the NP nanocomposites. SWNT has higher mechanical and electrical properties compared to MWNT. However, due to their higher specific surface area, the decreased permeability of SWNT NP makes resin impregnation more difficult. Three NPs with SWNT wt $\%$ of $0,60.6$ and 100 were selected based on statistical optimization method, to best represent the entire range. ${ }^{[17,66]}$

The SEM microstructures of the fracture surfaces are shown in Fig. 6. Compared to the well impregnated MWNT NP/EP nanocomposite, in both $60.6 \%$ SWNT NP/EP and $100 \%$ SWNT NP/EP nanocomposites, there are areas without resin impregnation, shown in Fig. $6 \mathrm{~B} 1$ and $\mathrm{C} 1$. The amount of EP impregnated into the nano-porous network was positively correlated to the NP's permeability. As the permeability was decreased, which was due to the increase of SWNT $w t^{\%} \%$ of the NP, the amount of resin impregnated into the NP was decreased. Fig. 6A3 shows the homogeneous epoxy impregnation into the porous area of the MWNT NP. However, in Fig. 6B3 and C3, nanotubes are observed completely not wetted by EP for the $60.6 \%$ SWNT NP/EP and 100\% SWNT NP/EP nanocomposites. The nanotubes in Fig. 6B3 and B3 appear to be bigger and longer compared to Fig. 6A3, due to the larger specific surface area of SWNTs to create the nanotube bundles. The densities of MWNT NP/EP, $60.6 \%$ SWNT NP/EP, and $100 \%$ SWNT NP/EP nanocomposites were $1.30,1.26$, and $1.40 \mathrm{~g} / \mathrm{cm} 3$, respectively. The density of $60.6 \%$ SWNT $\mathrm{NP} / \mathrm{EP}$ was lower than that of MWNT NP/EP due to non- 
uniform resin impregnation. Since uniform impregnation was not achieved in the $60.6 \%$ and $100 \%$ SWNT NP/EP nanocomposites, only their surface sheet resistances are measured. It was $18.5 \Omega / \mathrm{sq}$ for MWNT NP/EP, $0.11 \Omega / \mathrm{sq}$ for $60.6 \% \mathrm{SWNT} / \mathrm{NP} \mathrm{EP}$, and $0.055 \Omega / \mathrm{sq}$ for $100 \% \mathrm{SWNT}$ NP/ EP.
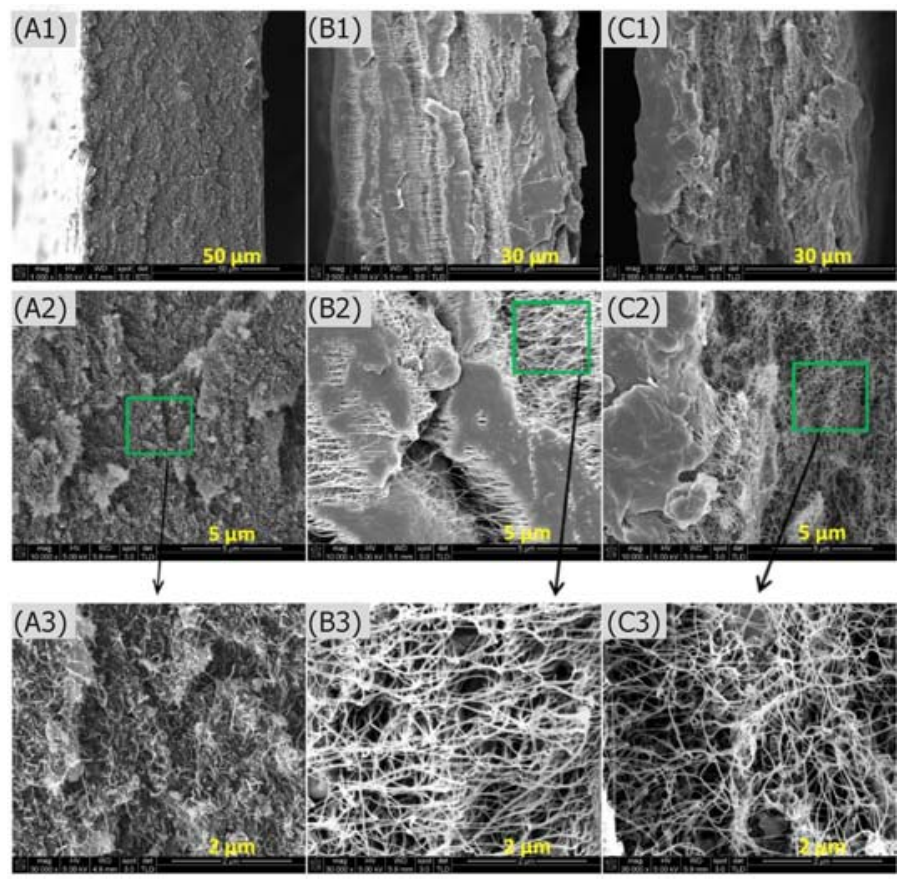

Fig. 6 SEM images of the fracture surfaces of different CNT NP/ epoxy nanocomposites, (A1-A3) MWNT NP/epoxy nanocomposite, (B1-B3) 60\% SWNT NP/epoxy nanocomposite, and (C1-C3) $100 \%$ SWNT NP/epoxy nanocomposite. Reproduced with permission.[17] (Copyright (C) 2018 Elsevier Ltd.)

Although only partial impregnation was obtained, the tensile strength of $60.6 \%$ SWNT NP/EP nanocomposite reached $136.4 \mathrm{MPa}$, and $200 \mathrm{MPa}$ for the $100 \%$ SWNT NP/EP nanocomposite, which was $65.3 \%$ and $142 \%$ improvement, respectively, compared to pure EP (82.5 MPa). Usually non-uniform CNT dispersion in polymer matrix leads to a decrease in the tensile properties. The increased tensile strength is because of the continuous rigid structure of SWNT NP (for both $60.6 \%$ and $100 \%$ SWNT NP). Their tensile strength and Young's modulus could be higher if the resin impregnation into SWNT NPs was improved. The strain at break is $10.1 \%$ for the MWNT NP/EP, 3.2\% for $60.6 \%$ SWNT NP/EP, and $4.5 \%$ for $100 \%$ SWNT NP/EP, which indicates the brittle property of the nanocomposites.

\subsubsection{TPU/NP nanocomposites}

Compared to the cross-linked EP matrix, TPU offers a better process flexibility because it can be used for high yield rate manufacturing processes like injection molding and extrusion. By changing the material composition (ratio of soft segment to hard segment), TPU can be tailored from elastomer to rigid solid, therefore is widely used in transportation, packaging, building and construction industries. ${ }^{[50]}$ Besides the ultrasonic infiltration, dip soaking was also used to impregnate TPU into the porous CNT NPs (both MWNT NP and 10\% SWNT NP) to fabricate thin nanocomposites. The polytetrahydrofuran (PTHF), 1, 4 Butanediol (BD), and 4,4 methylene diphenyl diisocyanate (MDI) were mixed at a molar ratio of 4: $1: 5$, with 5\% extra of MDI. CNT NP was dip soaked in the TPU monomer mixture in a glass Petri dish located on a hot plate for $10 \mathrm{~min}$. The synthetized PU was polyether type PU, and had an excellent abrasion resistance. The temperature of TPU mixture was controlled at $50{ }^{\circ} \mathrm{C}$ by a hot plate underneath. ${ }^{[41]}$ The average thickness was $52 \mu \mathrm{m}$ for MWNT NP, and $50 \mu \mathrm{m}$ for $10 \%$ SWNT NP measured by a Mitutoyo digital indicator. The thickness slightly decreased for the $10 \%$ SWNT NP due to the denser structure (lower porosity), when the same amount (1.8 g) of CNT was used to fabricate each piece of NP. The thickness swelled to a range of between 100 and $110 \mu \mathrm{m}$ after the TPU infiltration by both methods, which was also observed in the MWNT NP/EP nanocomposite fabrication.

TGA was used to analyze the quality of TPU impregnation into the NPs. The overlapped TGA curves for MWNT NP nanocomposites using these two methods (ultrasonic infiltration and dip soaking) indicated that the nanocomposites had the same MWNT wt\%. Using Eqs (1) and (2), CNT wt $\%$ of the MWNT NP TPU nanocomposite was calculated to be $26 \%$, which was similar to the CNT wt $\%$ of the well impregnated MWNT NP EP nanocomposite. ${ }^{[17]}$ The CNT wt $\%$ in the $10 \%$ SWNT NP TPU nanocomposite was calculated to be $27.2 \%$. It is slightly higher than $26 \%$, because less TPU was infiltrated into the $10 \%$ SWNT NP due to its lower porosity. The CNT wt $\%$ in the nanocomposite was significantly higher than the CNT percolation threshold $(0.1 \sim 3 \mathrm{wt} \%))^{[55,70]}$ Thus, the electrical properties of nanocomposite are expected to be significantly improved compared to the TPU matrix.

The tensile tests were carried out for NPs, pure TPU and nanocomposites. The TPU was purposely synthesized to have a high ductility using a polyol to chain extender molar ratio of $4: 1$, in order to balance the brittleness of CNT NP (the strain at break $<4.5 \%$ ),. The strain at the break of TPU reaches $800 \%$, but the tensile strength was only $1.2 \mathrm{MPa}$, and the Young's modulus was only 1.7 MPa. The MWNT NP TPU nanocomposite (prepared by dip soaking) had a tensile strength of $23.6 \mathrm{MPa}$, and a Young's modulus of 62.1 MPa. The $10 \%$ SWNT NP TPU nanocomposites reached the highest tensile strength (29.5 MPa) and Young's modulus $(123.6 \mathrm{MPa})$, which was $2170 \%$ and $7170 \%$ improvement compared to TPU due to the NP reinforcement. Its strain at break was $295.7 \%$. The van der Waals force between the continuous CNT NP and the TPU matrix led to the formation of strong and ductile nanocomposites. The significant modulus improvement was because of the NP $(720 \mathrm{MPa})$, and the ductility improvement was due to the TPU $(800 \%)$. Therefore, the NP TPU nanocomposite is an 
excellent combination of the weak ductile TPU and brittle NP.

The MWNT NP TPU nanocomposite prepared by dip soaking showed overall better mechanical properties compared to that prepared by ultrasonic infiltration (Fig. 7), because the strong ultrasonic effect led to damages in the NP, and introduced defects into the nanocomposite. Improvements on the nanocomposite manufactured by ultrasonic process are possible by optimizing the ultrasonic conditions. Another approach to improving the properties could be functionalization of the CNTs to promote the covalent bonding between CNTs and the TPU matrix.

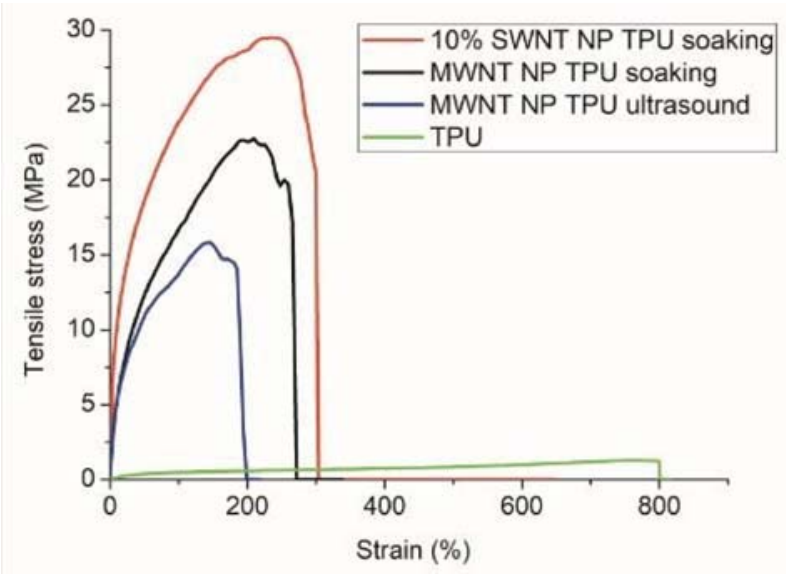

Fig. 7 Stress strain curves of different samples. Reproduced with permission. ${ }^{[41]}$ (Copyright (C) 2019 Elsevier Ltd.)

SEM fracture surface studies revelated that the MWNT NP TPU nanocomposites fabricated by ultrasonic infiltration and dip soaking methods are similar. The nanotubes were uniformly distributed in the TPU matrix, and no nanotube agglomerates were observed. The porous area in the MWNT NP had been filled by TPU, which indicated a good resin impregnation into the MWNT NP. Some observed nanotube pull-outs indicated that the interfacial bonding between nanotube and TPU was not strong.

Due to the ultrasonic wave which significantly facilitied the resin impregnation into porous media, the infiltration time was reduced to $4 \mathrm{~s}$, compared to $10 \mathrm{~min}$ using dip soaking. The mechanism was that ultrasonic energy with a high intensity could produce a strong agitation in liquid mediums. ${ }^{[65]}$ The cavitation effect and reduced effective viscosity facilitated the resin impregnation into CNT NP ${ }^{[17,69]}$ As the NP permeability was decreased, some voids appeared in the nanocomposite, but the majority of porous area was filled with TPU and uniform resin impregnation was achieved. Two co-continuous phases were present in the nanocomposites, which could affect the nanocomposite's mechanical and electrical properties. The nanocomposite density was $1.02 \mathrm{~kg} / \mathrm{m} 3$ for MWNT NP TPU, and $1.07 \mathrm{~kg} / \mathrm{m} 3$ for $10 \%$ SWNT NP TPU.

Because NP TPU nanocomposite can be melted, microinjection molding ( $\mu \mathrm{IM})$ was conducted to demonstrate its process flexibility. A microinjection molding machine
(LD30EH2, Sodick Plustech) was used. The maximum clamping force was 30 ton, and the maximum injection velocity was $250 \mathrm{~mm} / \mathrm{s}$. The process condition was as follows: melt temperature $240^{\circ} \mathrm{C}$, mold temperature $70^{\circ} \mathrm{C}$, max injection pressure $150 \mathrm{MPa}$, and packing pressure 120 $\mathrm{MPa}^{[41]}$ The microinjection-molded parts using the MWNT NP TPU and 5\% MWNT TPU (compounded) demonstrated the high process flexibility of the nanocomposites. The molded NP TPU nanocomposite samples were fabricated by chopped thin NP TPU nanocomposite pieces.

The tensile tests revealed that the molded NP TPU nanocomposite showed $154 \%$ and $1700 \%$ improvement in tensile strength and Young's modulus compared to pure TPU. It is stronger than the molded 5\% MWNT TPU composite due to higher MWNT wt\%. Since the continuous NP network was destroyed by chopping, the molded nanocomposite was not strong as the NP TPU nanocomposite.

\subsubsection{CNT NP/PDMS nanocomposites}

PDMS matrix was also selected to fabricate the NP nanocomposite to demonstrate the suitability of the ultrasonic assisted manufacturing processing for elastomers. The PDMS elastomer (SYLGAR ${ }^{\circledR} 184$ containing both silicone elastomer base and curing agent) was purchased from Dow Corning Corp, Midland, MI. Uniform resin impregnation was also observed for MWNT NP PDMS nanocomposites. Fig. 8A shows the SEM image for the cross-section of the nanocomposite after ultrasonic impregnation. It shows that the porous area in the MWNT NP is filled by the PDMS, which indicates uniform impregnation. TGA result showed the $27 \mathrm{wt} \% \mathrm{CNT}$ in the nanocomposite. The nanocomposites were impregnated with epoxy, TPU and PDMS resins of different viscosities exhibited similar cross-section uniformity, suggesting that the ultrasonic method was able to infiltrate resins within a viscosity range of $0.1 \sim 10 \mathrm{~Pa} \cdot \mathrm{s}$.

The processing flexibility of ultrasonically impregnated PDMS nanocomposites was demonstrated by injection molding with a tensile test specimen shown in Fig. 8B. Ultrasonically impregnated nanocomposites were injection molded into a dog bone shape tensile test specimen. Fig. 8C shows the SEM image of injection molded nanocomposites. The cross-section shows well-dispersed MWNTs after injection molding. Compounded $10 \mathrm{wt} \%$ MWNT + PDMS and pure PDMS were also injection molded to produce tensile test specimens.

Compared to the brittle MWNT NP (strain at break $4.5 \%$ ), the tensile testing studies revealed that the strain at break of PDMS reached $180 \%$ due to its elastomeric property. Due to the high and well-dispersed MWNT loading, the injection molded PDMS nanocomposite sample showed a $3100 \%$ increase in Young's modulus compared to pure PDMS. Compounded $10 \mathrm{wt} \%$ MWNT + PDMS had a $600 \%$ increase in Young's modulus compared to pure PDMS The electrical conductivity of the MWNT NP PDMS was 1 
$400 \mathrm{~S} \mathrm{~m}^{-1}$. This ductile and electrically conductive MWNT NP PDMS nanocomposite can be used for strain sensing application.
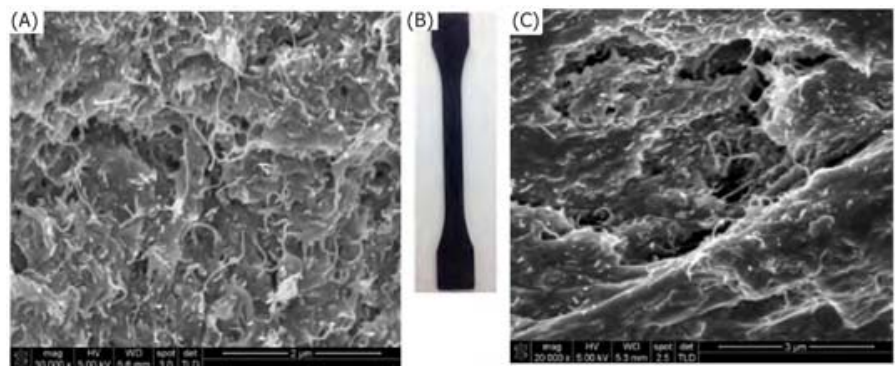

Fig. 8 (A) SEM cross-section morphology of MWNT NP/PDMS nanocomposite; (B) Injection molded sample of MWNT NP/PDMS nanocomposite; (C) SEM cross-section morphology of injection molded MWCNT/PDMS nanocomposite. Reproduced with permission. [40] (Copyright (C) 2018 Elsevier Ltd.)

\subsection{Abrasion property}

After ultrasonic impregnation and before curing, the CNT $\mathrm{NP} /$ polymer prepregs were coated onto the top of glass fiber reinforced polymer composite (GFPC) substrate and other substrates. Extra surface resin of the prepreg was able to bond the substrates after the complete curing procedure. The anti-abrasion properties of the nanocomposite coatings, including sand erosion resistance and scratch resistance, were evaluated. Improved abrasion resistance is important for the composites used in wind energy, sporting goods, electronic housing and automotive industries.

\subsubsection{Sand erosion resistance}

The sand erosion resistance in terms of erosion rate was measured and shown in Fig. 9 by conducting sand erosion test according to ASTM standard G76 95. The experiment step is shown in Fig. 9A. The sand erosion rate was the mass loss per second when the sample was under sand impingement. The unit was $\mathrm{mg} / \mathrm{s}$. A lower erosion rate means a better erosion resistance. GFPC was tested as a control, and it had the worst erosion resistance $6.547 \mathrm{mg} / \mathrm{s}$. The sand erosion rate of MWNT NP/epoxy coating was 1.8 $\mathrm{mg} / \mathrm{s}$, which was $167 \%$ lower than GFPC. Without nanocomposite coating, the GPFC surface is heavily eroded after sand impingement, Fig. 9B. This is due to (1) higher strength of the nanotubes compared to glass fibers, and (2) smaller nanotube spacing in the MWNT NP/ epoxy coating compared to the larger glass fiber spacing in the GFPC. The high loading (30.5 wt $\%$ ) interweaved nanotubes contact the erodent together and are able to effectively share the impact load during impingement. However, in GFPC, the glass fiber placing is comparable to the erodent size, leaving the epoxy resin between the glass fibers exposed to the erodent during impingement, thus cannot be effectively protected. ${ }^{[16,71]}$

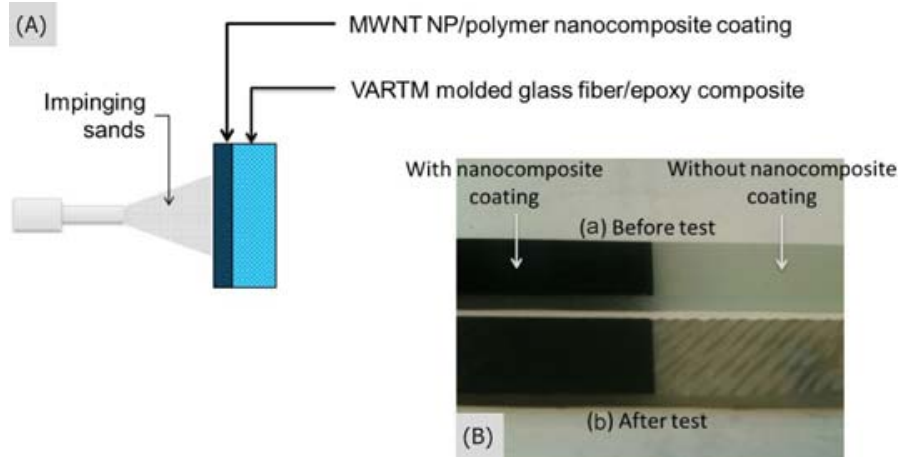

Fig. 9 (A) Sand erosion experiment setup; (B) Samples before and after test. (Modified from ref. [40])

Due to the rubbery property, pure TPU offers the best erosion resistance (the lowest erosion rate of $0.014 \mathrm{mg} / \mathrm{s}$ ) because it is able to bounce back the impinging sand particles. However, the mechanical strength of TPU is low (1.3 MPa). Thus, it is better to use the stronger CNT NP TPU nanocomposite as coating for sand erosion. The MWNT NP TPU and $10 \%$ SWNT NP TPU thin nanocomposite coating had similar erosion rates $(0.158$ and $0.140 \mathrm{mg} / \mathrm{s}$, respectively). Compared to the control group (GFPC), they were improved 40 and 45 times. The interweaved CNT network with a small nanotube spacing $(<100 \mathrm{~nm})$, and the rubbery TPU matrix contributed to this significant improvement. ${ }^{[72,73]}$ Similarly, the MWNT NP/PDMS coating had an erosion rate of $0.145 \mathrm{mg} / \mathrm{s}$ due to the rubbery PDMS matrix and NP reinforcement. The superior erosion resistance of the nanocomposite coating is very promising for surface protection application in wind turbine and sporting goods industries.

\subsubsection{Scratch resistance}

Besides the erosion resistance, the scratch resistance of nanocomposite coating is also evaluated for potential applications in electronic housing and sporting goods industries. The device was a TABER ${ }^{\circledR}$ Model 710 scratch tester (Taber Industries, North Tonawanda, NY) installed with a conical indenter with a $0.1 \mathrm{~mm}$ diameter tip. The control samples included ultra-high molecular weight polyethylene (UHMWPE), cured epoxy, iPad cover (aluminum), GFPC and carbon fiber reinforced polymer composite (CFPC).

When the indenter on the scratch tester moved under the applied $20 \mathrm{~N}$ load, a scratch track was made on the material surface. From the profile of the deformation after one scratch, the depth of the scratch mark was measured. The scratch depth variations of different samples are shown in Fig. 10. Among them, the MWNT NP/EP nanocomposite showed the lowest scratch depth, indicating the best anti-scratch performance. Due to the rubbery nature, the TPU or PDMS nanocomposites were not tested for scratch resistance. 


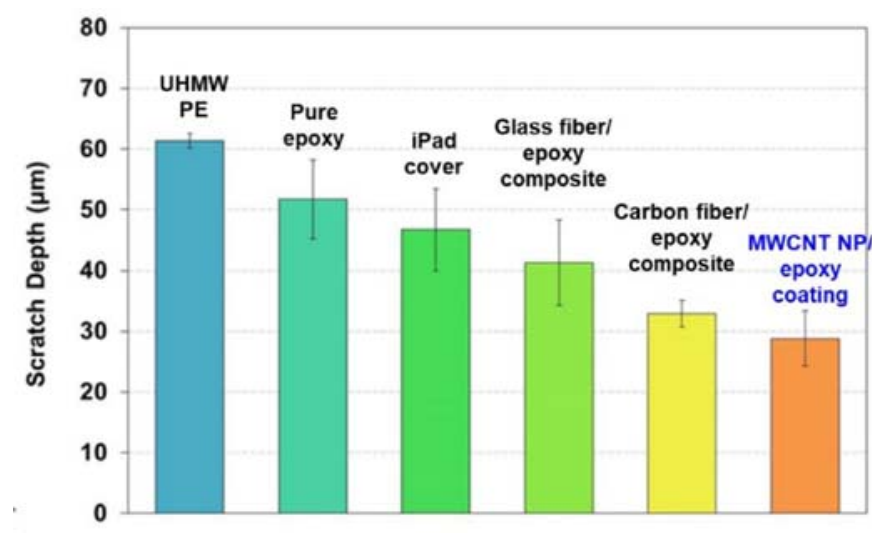

Fig. 10 Scratch depth of MWNT NP/epoxy and control samples. Reproduced with permission. [40] (Copyright (C) 2018 Elsevier Ltd.)

\subsection{Electrical and EMI shielding properties}

The variation of EMI SE over the frequency range of 30 $\mathrm{MHz}$ to $1.5 \mathrm{GHz}$ was tested for the MWNT NP and nanocomposites, and compounded nanocomposite, as well as a commercial carbon fiber (CF) mat, Fig. 11. The $52 \mu \mathrm{m}$ thick MWNT NP reached an average EMI SE of $30 \mathrm{~dB}$. The $258 \mu \mathrm{m}$ thick commercial $\mathrm{CF}$ mat had a denser fiber packing in its woven texture than NP, as indicated by their respective porosity and density. Thus, the CF mat demonstrated an average EMI SE of $57 \mathrm{~dB}$, but its thickness was five times higher than the MWNT NP. The high EMI $\mathrm{SE}$ value of $\mathrm{CF}$ mat reached the limit of the measuring device, thus increasing the variance of the measurement. The MWNT NP/EP and MWNT NP/TPU nanocomposites had an average EMI SE of $23 \mathrm{~dB}$ over the frequency range of $30 \mathrm{MHz} 1.5 \mathrm{GHz}$. The MWNT NP/PDMS nanocomposite reached a lower EMI SE of 17 20 dB. For the high loading CNT reinforced polymer nanocomposite, absorption of EM waves contributes to the majority of EMI SE.

Dynamic mechanical analysis showed that the CNT $\mathrm{NP} /$ polymer nanocomposites had a high loss tangent tan $\partial$, which indicated that the EM waves were absorbed by the nanocomposites, and then converted into heat. ${ }^{[74]}$ The NP nanocomposites had a thickness of 100 to $110 \mu \mathrm{m}$, thus were regarded as thin nanocomposite. Due to the much lower CNT weight percentage, the $10 \mathrm{wt} \%$ MWNT PDMS sample only reached an average EMI SE of $6 \mathrm{~dB}$. Although the EMI SE was decreased after resin impregnation due to a swelling and resin rich layer, the MWNT NP/EP and MWNT NP/TPU nanocomposites still met the EMI SE requirement $(20 \mathrm{~dB})$ for many commercial applications and could be useful, for example, in electronics housing or cell phone cover. $^{[75,76]}$

By adding $10 \%$ SWNT, the average EMI SE of CNT NP increases to $41 \mathrm{~dB}$, compared to MWNT NP (average 29 $\mathrm{dB}$ ), which are shown in Fig. 11. It is because of SWNTs'higher electrical conductivity and higher aspect ratio (thus a lower NP porosity), which improved the absorption of electromagnetic waves. The absorption accounted for $99 \%$ of the EMI SE of the NP, and the reflection accounted for $1 \%$. The multi reflection was negligible.

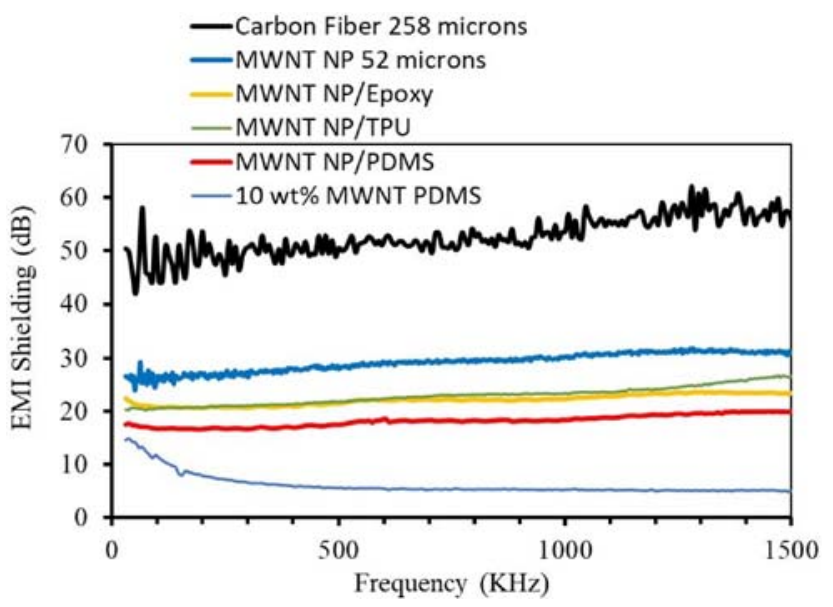

Fig. 11 EMI SE of MWNT NP, MWNT NP/polymer nanocomposites, and carbon fiber. (Modified from ref. [40])

Due to the high loading (26 wt $\%$ ) and homogeneous dispersion of CNTs in the TPU matrix and the connecting of CNTs, the average EMI SE of $10 \%$ SWNT NP TPU reached $37 \mathrm{~dB}$, which was high at a thickness of $100 \mu \mathrm{m}$ compared to previous work of CNT TPU nanocomposites. ${ }^{[74,77,78]}$ It is a significantly higher EMI SE than the commercial requirement for automotive and electronic housing applications $(20 \mathrm{~dB})$. It decreased $4 \mathrm{~dB}$ compared to the $10 \%$ SWNT NP, because the TPU impregnation swelled the NP by $100 \%$. Similarly, the average EMI SE of MWNT NP TPU was $23 \mathrm{~dB}$, i.e. a 6 $\mathrm{dB}$ decrease compared to the MWNT NP. After TPU impregnation into NP, the nanotube network became less dense, which resulted in a less absorption of the electromagnetic waves, and thus a lower EMI SE value.

Because of high ductility, the TPU nanocomposites can be stretched to $50 \%$ or $100 \%$ strain. For the $10 \%$ SWNT NP TPU, the EMI SE does not decrease significantly after stretching, as shown in Fig. 12. It is because although stretching could make the nanotube network less dense and break some conducting paths, the SWNTs with a high conductivity and high aspect ratio could maintain the EMI SE of the nanocomposites. While the EMI SE of the MWNT NP TPU nanocomposite decreased from 23 to $20 \mathrm{~dB}$ after stretching to $50 \%$ or $100 \%$ strain, because MWNTs with a lower electrical conductivity and aspect ratio could not maintain the EMI SE as well as SWNTs after large deformation. The high and stable EMI SE of 10\% SWNT NP TPU nanocomposite had the potential to be applied in aerospace and automotive industries.

\subsection{Strain sensing property}

Based on the superior tensile characteristics, the stretchable MWNT NP/PDMS nanocomposite was chosen for epidermal sensors. PDMS is selected as the polymer matrix because it is most commonly used and is considered to be the best choice for a strain sensor due to its high deformation sensitivity, chemical stability, perfect elasticity, good transparency, and 


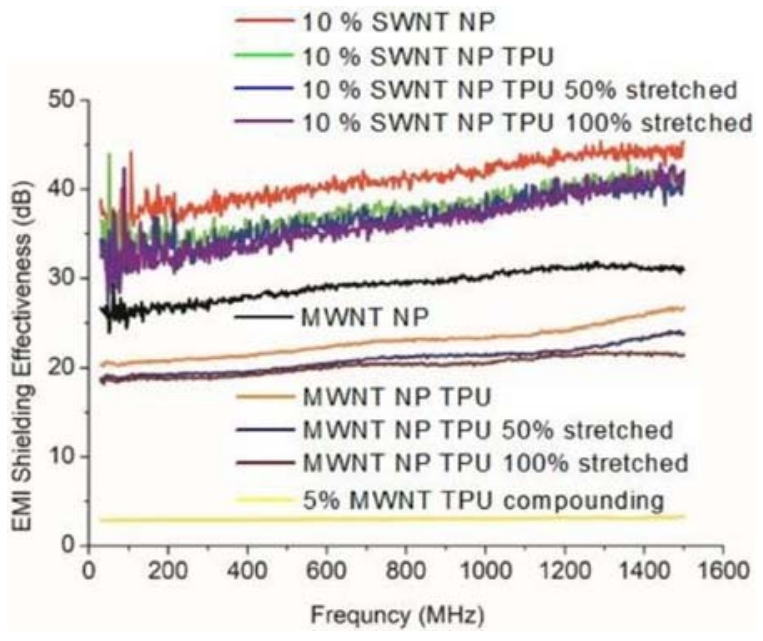

Fig. 12 EMI SE of CNT NP, CNT NP/TPU before and after stretching (50\%, 100\% strain). Reproduced with permission. [41] (Copyright (C) 2019 Elsevier Ltd.)

biomedical compatibility among these elastomeric materials. ${ }^{[79,80]}$ With the rapid development of wearable devices, epidermal sensors and flexible batteries, the fabrication of homogeneous nanocomposites is an imperative and meaningful challenge.

\subsubsection{Electrical resistance-strain behavior}

Compared to the conductive networks built from separately dispersed or locally aggregated nanofillers with relatively low contents, homogeneously dispersed MWNTs in the PDMS matrix guaranteed a high electrical conductivity with a significantly improved uniformity. Furthermore, the stretchable MWNT NP/ PDMS nanocomposite also showed a superior electrical resistance-strain behavior (also called piezo-resistive effect) due to the displacement and rearrangement of MWNTs within the PDMS matrix under the tensile force. The electrical conductivity of free- standing MWNT NP was $3500 \mathrm{~S} \cdot \mathrm{m}^{-1}$, while that of the MWNT NP/ PDMS nanocomposite was $1430 \mathrm{~S} \cdot \mathrm{m}^{-1}$. The drop of electrical conductivity was expected due to the swell of the MWNT NP after PDMS impregnation. This conductivity was much higher than those CNT nanocomposites fabricated by conventional methods, e. g. self-assembly, melt compounding, and solution dispersion. ${ }^{[81,82]}$ The negligible current changes after specific scratching cycles indicated that the electrical conductivity of the stretchable NP nanocomposites had a high uniformity across the sample thickness.

The resistance strain behavior of MWNT NP/PDMS nanocomposite based strain sensors under a stretch release condition was evaluated using a computer controlled tensile testing machine (RSA3) and a semiconductor characterization system (4200-SCS). The current voltage responses of the nanocomposite strain sensors under different static strains up to $100 \%$ were completely steady, which indicated a constant resistance under each strain. As shown in Fig. 13A, the relative resistance change $\left(\Delta R / R_{0}, R_{0}\right.$ was the initial resistance before stretching) increased near linearly from $8.18 \%$ at $10 \%$ strain to $176.74 \%$ at $80 \%$ strain, before sharply rising to $643.75 \%$ at $100 \%$ strain. Thus, the linear sensing range of this MWNT NP/PDMS nanocomposite based strain sensor can reach $80 \%$ strain without an abrupt resistance increase, which meets the demand of an epidermal strain sensor for human motion detection (exceeding 50\% strain).

Higher, stable, and repeatable resistance changes were preferred to improve the piezo-resistive sensitivity for strain sensing applications. The piezo-resistive sensitivity of the strain sensors can also be represented with the gauge factor $(G F)$, which is derived from $G F=\Delta R /\left(\varepsilon R_{0}\right)$, where $\varepsilon$ is the applied strain. The variation of the $G F$ value at different strains presents a consistent increasing trend with that in Fig. $13 \mathrm{~A}$. The $G F$ value of the nanocomposite based strain sensor slightly increased from 0.82 at $10 \%$ strain to 2.21 at $80 \%$ strain, indicating stable and compact electrically conductive pathways within the sensor at such high strains. With a further increase in applied strain, the $G F$ value increased to 6.44 at $100 \%$ strain, revealing the more enhanced piezo-resistive effects than those of previously reported strain sensors also fabricated with CNTs $(G F=0.65) \cdot{ }^{[83]}$ Due to the high MWNT content and the homogeneous dispersion of MWNTs in the nanocomposite, numerous points of contact existed in the 3D structure within the sensor, which led to a linear sensing capability at strains up to $80 \%$. Moreover, the maximum sensible strain (ca.160\%) was much higher than that of most previously reported CNT based strain sensors (typical maximum strain of less than $100 \%$ ). To further investigate the resistance strain behaviorofthe MWNTNP/PDMS nanocomposite based strain sensors, relative resistance changes were monitored over the course of multiple stretch-release cycles (up to 100). The small decline in the relative electrical resistance at various strains and cycles presented in Fig. 13B implies a high cycling stability, repeatability, and durability of this new strain sensor.

The frequency response and recoverability of the nanocomposite strain sensor were studied further under a dynamic strain of $30 \%$ with two different frequencies: 0.1 and $0.5 \mathrm{~Hz}$. The output resistance curves were almost the same as the input strain curves when the frequency was 0.1 $\mathrm{Hz}$ (Fig. 13C). Even when the frequency was increased to $0.5 \mathrm{~Hz}$, the output resistance curves remained stable and harmonical with input strain curves (Fig. 13D). The observed small mismatches and shape variations of the output resistance curves could be attributed to the hysteresis caused by elastic buffer effects of the stretchable PDMS matrix. The very low hysteresis performance of the sensor was a result of the compact structure of MWNTs and strong interaction forces between the conductive pathways and PDMS matrix in the NP. However, the hysteresis of strain sensors would become much more apparent at a very large strain, e.g. $100 \%$ strain. 
(A)

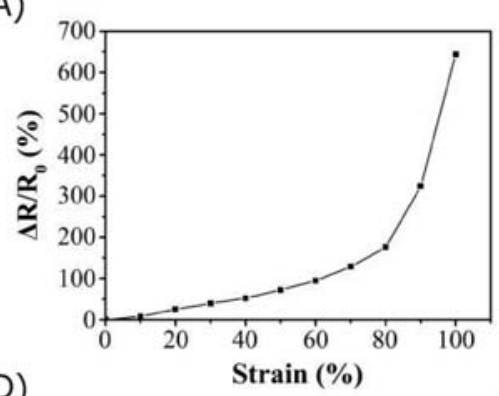

(D)

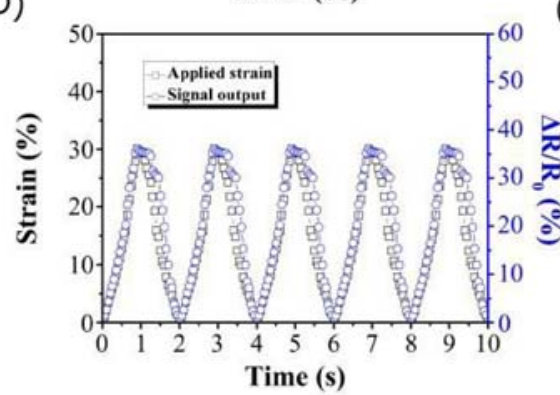

(B)

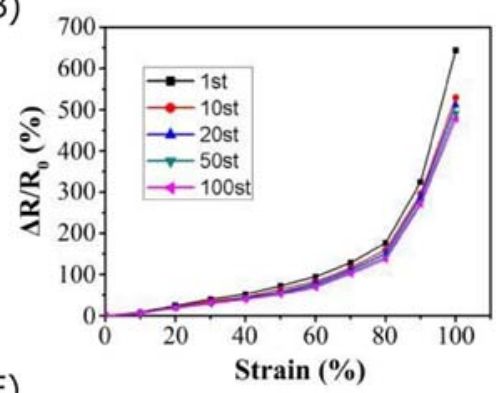

$(\mathrm{E})$

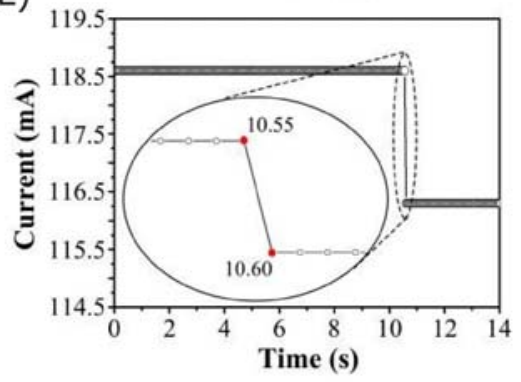

(C)

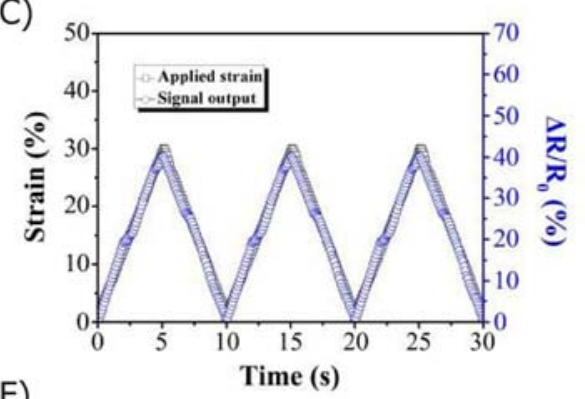

(F)

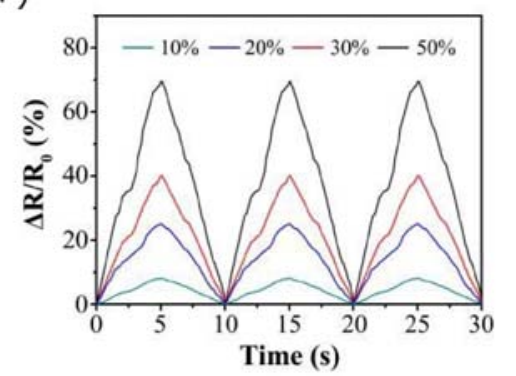

Fig. 13 Electrical characteristics, sensing mechanism and resistance responses of stretchable MWNT NP/PDMS composite-based strain sensors. Electrical resistance response (A) versus strain. Repeatability after multiple stretch-release cycles (B) Frequency responses at different frequencies 0.1 (C) and 0.5 (D) $\mathrm{Hz}(30 \%$ strain). Real-time fast response ( $\approx 50 \mathrm{~ms})$ under an instant stimulus (E). Relative resistance-strain behavior under different strains (strain frequency $0.1 \mathrm{~Hz}$ ) (F). Reproduced with permission. ${ }^{[42]}$ (Copyright $\odot 2018$ IOP Publishing Ltd.)

Fig. 13E shows the real-time fast response of MWNT NP/PDMS nanocomposite-based strain sensors under an instant stimulus. With an input voltage of $5 \mathrm{~V}$, a tiny touch on the sensor caused the current drop from 118.6 to 116.3 $\mathrm{mA}$ within $0.1 \mathrm{~s}$, indicating a response time less than $100 \mathrm{~ms}$ (ca. $50 \mathrm{~ms}$ ). The resistance strain behaviors of the nanocomposite sensor under various dynamic strains with a frequency of $0.1 \mathrm{~Hz}$ are shown in Fig. 13F. Although the output resistance curves and cycling responses were stable and continuous under different strains, the curves were not smooth as the strain increased from $10 \%$ to $50 \%$, indicating a visible hysteresis.

\subsubsection{Human motion detection application}

The MWNT NP/PDMS nanocomposite based strain sensor is sensitive to the vibration and strain changes caused by human motions. For demonstration purposes, the strain sensors were directly attached on the skin of the index finger, wrist joint, and elbow joint to test the bending and releasing movements. The real- time relative resistance changes with an applied voltage of $5 \mathrm{~V}$ are presented in Fig. 14. The background noises corresponded to the muscle tremble and some unavoidable ambient noise that can be detected by the strain sensor.

Fig. 14A shows the motion detection for the proximal interphalangeal joint of the index finger. The finger was repeatedly bent at a frequency of around $0.5 \mathrm{~Hz}$ and the response behavior of the strain sensor was recorded. The strain sensor was stretched when the finger was bent at a certain angle and then released. The resistance increased and decreased periodically during the bending and releasing processes. The response to the motion of the strain sensor was rapid and quite stable, Fig. 14A. When the strain sensor was applied to monitor the bending and releasing of the wrist joint, which involved larger and more diverse deformations, significant resistance changes were observed, Fig. 14B. ${ }^{[84]}$ The relative resistance changes increased from $\sim 10 \%$ in Fig. $14 \mathrm{~A}$ to $>30 \%$ in Fig. 14B. Similar to the detection shown in Fig. 14A, the observed motion response was rapid and sharp. Fig. 14C shows the testing of elbow joint bending, for which the strain sensor was stretched at three different bending angles $(\approx 45,90$, and $135^{\circ}$ ) and released when the elbow joint was straightened. The relative resistance change of the strain sensor increased with increasing the bending angle, which showed that the sensor could distinguish the different bending angles of the elbow joint. Furthermore, the resistance of the strain sensor was constant when the elbow was held at a certain bending angle. After straightening the elbow joint, the electrical signal would return to the original measurement. Although the responses exhibited a small signal drift, the strain sensor exhibited very good repeatability and sensitivity in the motion detection. The signal drift in the responses could be caused by the hysteresis of the strain sensor. The varying degrees of muscle movements could have also contributed to the drift. With an ultrathin thickness of $100 \mu \mathrm{m}$, the MWNT NP/PDMS nanocomposite based strain sensor can be directly attached onto human skin with little foreign body sensation and discomfort. The ultrathin thickness makes the strain sensor useful for applications with a space limitation. 


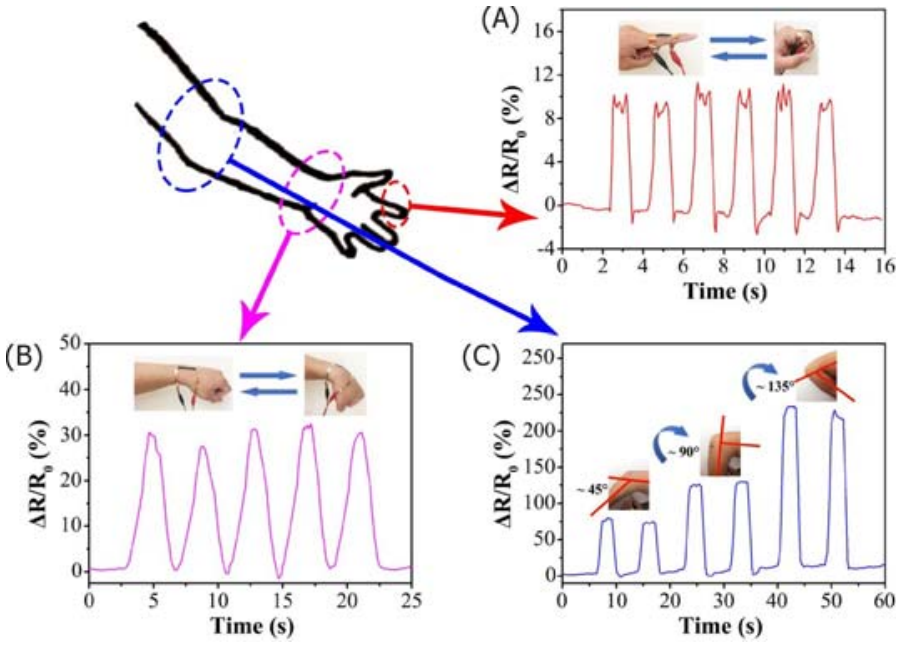

Fig. 14 Real-time human motion detection of the MWNT NP/PDMS nanocomposite-based strain sensor. (A) Relative resistance changes versus time during bending and releasing of the index finger with the inset showing the sensor directly attached on the index finger. (B) Real time detection of the wrist joint movements with the inset showing the sensor directly attached on the wrist joint. (C) Relative resistance changes versus time when the elbow joint was bent at different angles with the insets showing the sensor attached on the elbow joint at bending angles of around $45^{\circ}, 90^{\circ}$, and $135^{\circ}$. Reproduced with permission. ${ }^{[42]}$ (Copyright (C) 2018 IOP Publishing Ltd.)

\section{Conclusions and future work}

This paper discusses novel ultrasonic process to fabricate carbon nanotube nanopaper polymer nanocomposites. Different types of polymers including thermoset EP, elastomer PDMS and thermoplastic PU were used as matrix to impregnate different NPs including MWNT NP or SWNT NP to form nanocomposites with different functionalities. Performance improvements of the nanocomposites were discussed, and their applications towards a wide range of industries including aerospace, wind energy, electronic housing, and strain sensor, etc. were indicated.

The ultrasonic infiltration process with a lower ultrasound amplitude $(25 \mu \mathrm{m})$ and lower contact pressure (40 psi) resulted in higher tensile properties of MWNT $\mathrm{NP} /$ epoxy nanocomposite, because there was less damage onto NP during resin impregnation. Uniform resin impregnation (including EP, TPU and PDMS) into MWNT NP were achieved within a wide range of resin viscosity (0.166 to $10 \mathrm{~Pa} \cdot \mathrm{s})$. TGA results showed that the CNT weight percentage was from 27 to $30 \mathrm{wt} \%$ in the uniformly dispersed nanocomposites. The infiltration time was reduced to 4 seconds, significantly lower than the processing time of VARTM method ( $>1$ hour).

Beside MWNT NP, hybrid NPs (mixture of MWNT and SWNT) were evaluated to compare the relative advantages of both NPs. As the SWNT wt $\%$ increased in the NP, the porosity and permeability decreased to a point where only partial resin impregnation was possible, which limited the improvement in nanocomposite properties. Tensile strength of MWNT NP/epoxy nanocomposite was $105 \mathrm{MPa}$, 136.4 MPa for $60.6 \%$ SWNT NP/ epoxy nanocomposite was, and $200 \mathrm{MPa}$ for $100 \%$ SWNT NP/epoxy nanocomposite, which were $27.2 \%, 65.3 \%$ and $142 \%$ improvements, respectively, compared to epoxy (82.5 MPa) due to the strong continuous NP structure.

The 10\% SWNT NP TPU nanocomposite reached a tensile strength of $29.5 \mathrm{MPa}$ and a Young's modulus of 123.6 MPa, which were $2170 \%$ and $7170 \%$ improvements, respectively, compared to TPU, and reached the strain at break of $296 \%$. It is an excellent combination of ductile but weak TPU and brittle NP. The MWNT NP PDMS nanocomposite reached $3100 \%$ increase in Young's modulus compared to pure PDMS, and the strain at break of $180 \%$ due to its elastomeric property.

The NP nanocomposites can be coated on the GFPC substrate, and demonstrate superior abrasion resistance due to the interweaved CNT network. The MWNT NP/PDMS and MWNT NP/TPU nanocomposite coating improved the sand erosion resistance 45 times, due to the rubbery nature of PDMS or TPU matrices, which greatly reduced the damage of impinging sand particles. Due to the brittle property, the MWNT NP/epoxy improved the sand erosion resistance for $167 \%$, and its scratch resistance was the best among all other polymer and composite samples. The superior abrasion resistance of NP nanocomposite could find potential applications in wind energy, sporting goods, and electronic housing industries.

The EMI shielding of $100 \%$ SWNT NP ( $44 \mu \mathrm{m}$ thick) reached $57 \mathrm{~dB}$, which was higher than commercial carbon fiber perform $(51 \mathrm{~dB}, 258 \mu \mathrm{m}$ thick). This was because of the SWNTs' higher electrical conductivity and higher aspect ratio (thus lower NP porosity), which improved the absorption of electromagnetic waves. 10\% SWNT NP TPU nanocomposite demonstrated high and stable EMI shielding $(35 \mathrm{~dB})$ before and after large deformation $(100 \%$ strain extension) at a thickness of $100 \mu \mathrm{m}$. MWNT NP/TPU and MWNT NP/epoxy nanocomposites reached an average EMI shielding of $22 \mathrm{~dB}$ satisfying the requirement of commercial electronic housing or cell phone cover $(20 \mathrm{~dB})$.

For the strain sensing application, the MWNT NP/ PDMS nanocomposite exhibited high (1 $\left.430 \mathrm{~S} \mathrm{~m}^{-1}\right)$ and uniform (consistent across thickness) electrical conductivity, large linear sensing range (up to $80 \%$ strain) and sensible strain (up to $160 \%$ strain), and cyclic stability ( $>100$ cycles). Real-time motion detections of the index finger, wrist joint, and elbow joint successfully demonstrated its applicability as an epidermal strain sensor

To summarize, this method provides a new insight into the fabrication of nanocomposites with highly loaded and uniformly dispersed CNTs not achievable by conventional methods, and the rationally designed epidermal strain sensors with a promise for emerging human-interactive applications. The NP/polymer prepreg can be coated on 
glass fiber composites, carbon fiber composites or plastic substrates to provide excellent abrasion resistance and EMI shielding for wind energy, automotive, electronic housing, and aerospace markets.

Besides coating applications, MWNT NP/TPU nanocomposite was successfully processed by injection molding or extrusion, which offered excellent mechanical and electrical improvements compared to plastics. The MWNT NP/PDMS thin nanocomposite demonstrated excellent strain sensing properties, and is highly applicable for human motion detection application.

The potential applications of the nanocomposites produced from this technique are still under investigations. Meanwhile, to include other functional fillers together with carbon nanospecies in the nanopapers is also needed for achieving multifunctions.

\section{Acknowledgements}

The authors gratefully thank the financial support of Beijing Natural Science Foundation (No. 2204090), and the Talents Introduction Project in Beijing University of Chemical Technology (No. buctrc201909).

\section{Notes}

The authors declare no competing financial interest.

\section{References}

[1] E. T. Thostenson and T. W. Chou, J. Phys. D Appl. Phys., 2002, 35(16), 77-80.

[2] M. F. Yu, O. Lourie, M. J. Dyer, K. Moloni, T. F. Kelly and R. S. Ruoff, Science, 2000, 287(5453), 637-640.

[3] Q. W. Li, Y. Li, X. F. Zhang, S. B. Chikkannanavar, Y. H. Zhao, A. M. Dangelewicz, L. X. Zheng, S. K. Doorn, Q. X. Jia, D. E. Peterson, P. N. Arendt and Y. T. Zhu, Adv. Mater., 2007, 19 (20), 3358-3363.

[4] E. Pop, D. Mann, Q. Wang, K. Goodson and H. Dai, Nano Lett., 2006, 6(1), 96-100.

[5] P. Kim, L. Shi, A. Majumdar and P. L. McEuen, Phys. Rev. Lett., 2001, 87(21), 215502.

[6] L. Liu, W. Ma and Z. Zhang, Small, 2011, 7(11), 1504-1520.

[7] J. N. Coleman, U. Khan, W. J. Blau and Y. K. Gun' ko, Carbon, 2006, 44(9), 1624-1652.

[8] P. E. Lopes, F. van Hattum, C. M. C. Pereira, P. J. R. O. Nóvoa, S. Forero and F. Hepp, Compos. Struct., 2010, 92(6), 1291-1298.

[9] Q. Cheng, J. Bao, J. Park, Z. Liang, C. Zhang and B. Wang, Adv. Funct. Mater., 2009, 19(20), 3219-3225.

[10] P. Pötschke, T. D. Fornes and D. R. Paul, Polymer, 2002, 43(11), 3247-3255.

[11] Z. Fan and S. G. Advani, J. Rheol., 2007, 51(4), 585-604.

[12] L. Song, L. Ci, L. Lv, Z. Zhou, X. Yan and D. Liu, Adv. Mater., 2004, 16(17), 1529-1534.

[13] W. Ma, L. Song, R. Yang, T. Zhang, Y. Zhao and L. Sun, Nano Lett., 2007, 7(8), 2307-2311.

[14] L. Y. Li, I. A. Kinloch and A. H. Windle, Science, 2004, 304
(5668), 276-278.

[15] K. Koziol, J. Vilatela, A. Moisala, M. Motta, P. Cunniff and M. Sennett, Science, 2007, 318(5858), 1892-1895.

[16] D. Zhang, E. Cabrera, Y. Zhao, Z. Zhao, J. M. Castro and L. J. Lee, Adv. Polym. Technol., 2018, 37(6), 1878-1885.

[17] D. Zhang, M. G. Villarreal, E. Cabrera, A. Benatar, L. J. Lee and J. M. Castro, Compos. Part B, 2019, 159, 327-335.

[18] Q. Cheng, B. Wang, C. Zhang and Z. Liang, Small, 2010, 6(6), 763-767.

[19] X. Zhang, Adv. Mater., 2008, 20(21), 4140-4144.

[20] X. Zhang, K. Jiang, C. Feng, P. Liu, L. Zhang, J. Kong, T. Zhang, Q. Li and S. Fan, Adv. Mater., 2006, 18(12), 1505-1510.

[21] M. D. Rein, O. Breuer and H. D. Wagner, Compos. Sci. Technol., 2011, 71(3), 373-381.

[22] P. Dharap, Z. Li, S. Nagarajaiah and E. V. Barrera, Nanotechnology, 2004, 15(3), 379-382.

[23] P. J. Cottinet, M. Q. Le, J. Degraff, C. Souders, Z. Liang, B. Wang and C. Zhang, Sensor. Actuat. A-Phys., 2013, 194, 252258.

[24] I. W. Chen, P. J. Cottinet, S. Y. Tsai, B. Foster, R. Liang, B. Wang and C. Zhang, Sensor. Actuat. B, 2012, 171, 515-521.

[25] R. Smajda, Á. Kukovecz, Z. Kónya and I. Kiricsi, Carbon, 2007, 45(6), 1176-1184.

[26] P. Slobodian, P. Riha, A. Lengálová, P. Svoboda and P. Sáha, Carbon, 2011, 49(7), 2499-2507.

[27] H. Chu, Z. Zhang, Y. Liu and J. Leng, Carbon, 2014, 66, 154163.

[28] J. H. Han, H. Zhang, M. J. Chen, G. R. Wang and Z. Zhang, Compos. Sci. Technol., 2014, 103, 63-71. B. Fernandez-d'Arlas, U. Khan, L. Rueda, J. N. Coleman, I. Mondragon, M. A. Corcuera and A. Eceiza, Compos. Sci. Technol., 2011, 71(8), 1030-1038.

[30] Y. Martinez-Rubi, B. Ashrafi, M. B. Jakubinek, S. Zou, K. Laqua, M. Barnes and B. Simard, ACS Appl. Mater. Inter., 2017, 9(36), 30840-30849.

[31] Q. F. Cheng, J. P. Wang, J. J. Wen, C. H. Liu, K. L. Jiang, Q. Q. Li and S. S. Fan, Carbon, 2010, 48(1), 260-266.

[32] Z. Li, J. G. Park and Z. Liang, Adv. Eng. Mater., 2016, 18(8), 1460-1468.

[33] N. Nguyen, A. Hao, J. G. Park and R. Liang, Adv. Eng. Mater., 2016, 18(11), 1906-1912.

[34] C. Y. Chang, E. M. Phillips, R. Liang, S. W. Tozer, B. Wang, C. Zhang and H. T. Chiu, J. Appl. Polym. Sci., 2013, 128(3), 13601368.

[35] B. Fernandez-d'Arlas, U. Khan, L. Rueda, L. Martin, J. A. Ramos, J. N. Coleman, M. L. Gonzalez, A. Valea, I. Mondragon, M. A. Corcuera and A. Eceiza, Compos. Sci. Technol., 2012, 72(2), 235-242.

[36] P. Slobodian, P. Riha and P. Saha, Carbon, 2012, 50(10), 34463453.

[37] S. Wang, R. Downes, C. Young, D. Haldane, A. Hao and R. Liang, Adv. Eng. Mater., 2015, 17(10), 1442-1453.

[38] S. Wang, D. Haldane, R. Liang, J. Smithyman, C. Zhang and B. Wang, Nanotechnology, 2013, 24(1), 015704.

[39] L. J. Sweetman, L. Nghiem, I. Chironi, G. Triani and S. F. 
Ralph, J. Mater. Chem., 2012, 22(27), 13800-13810.

[40] Y. Zhao, E. D. Cabrera, D. Zhang, J. Sun, T. Kuang, W. Yang, M. J. Lertola, A. Benatar, J. M. Castro and L. J. Lee, Polymer, 2018, 156, 85-94.

[41] D. Zhang, H. Yang, J. Pan, B. Lewis, W. Zhou, K. Cai, A. Benatar, L. J. Lee and J. M. Castro, Compos. Part B, 2019, 182, 107646.

[42] J. Sun, Y. Zhao, Z. Yang, J. Shen, E. Cabrera, M. J. Lertola, W. Yang, D. Zhang, A. Benatar, J. M. Castro and D. Wu, Nanotechnology, 2018, 29(35), 355304.

[43] I. Alig, D. Lellinger, S. M. Dudkin and P. Pötschke, Polymer, 2007, 48(4), 1020-1029.

[44] K. Prashantha, J. Soulestin, M. F. Lacrampe, P. Krawczak, G. Dupin and M. Claes, Compos. Sci. Technol., 2009, 69(11-12), 1756-1763.

[45] W. Tang, M. H. Santare and S. G. Advani, Carbon, 2003, 41 (14), 2779-2785.

[46] P. Pötschke, A. R. Bhattacharyya and A. Janke, Carbon, 2004, 42(5-6), 965-969.

[47] S. Bellayer, J. W. Gilman, N. Eidelman, S. Bourbigot, X. Flambard, D. M. Fox, H. C. De Long and P. C. Trulove, $A d v$. Funct. Mater., 2005, 15(6), 910-916.

[48] M. Arjmand, T. Apperley, M. Okoniewski and U. Sundararaj, Carbon, 2012, 50(14), 5126-5134.

[49] J. Sun, J. Zhuang, J. Shi, S. Kormakov, Y. Liu, Z. Yang and D. Wu, J. Mater. Sci., 2019, 54(11), 8436-8449.

[50] D. Randall and S. Lee, The polyurethanes book. New York: John Wiley \& Sons Ltd., 2002, 1-477.

[51] W. Chen, X. Tao and Y. Liu, Compos. Sci. Technol., 2006, 66 (15), 3029-3034.

[52] W. Wohlleben, M. W. Meier, S. Vogel, R. Landsiedel, G. Cox, S. Hirth and Z. Tomovic, Nanoscale, 2013, 5(1), 369-380.

[53] Y. Geng, M. Y. Liu, J. Li, X. M. Shi and J. K. Kim, Compos. Part A, 2008, 39(12), 1876-1883.

[54] M. Abdalla, D. Dean, M. Theodore, J. Fielding, E. Nyairo and G. Price, Polymer, 2010, 51(7), 1614-1620.

[55] R. Zhang, A. Dowden, H. Deng, M. Baxendale and T. Peijs, Compos. Sci. Technol., 2009, 69(10), 1499-1504.

[56] T. B. Richardson, M. A. Mosiewicki, C. Uzunpinar, N. E. Marcovich, M. I. Aranguren, F. Kilinc-Balci, R. M. Broughton Jr and M. L. Auad, Polym. Compos., 2011, 32(3), 455-463.

[57] J. Ryszkowska, M. Jurczyk-Kowalska, T. Szymborski and K. J. Kurzydłowski, Phys. E Low-dimens. Syst. Nanostruct., 2007, 39 (1), 124-127.

[58] S. D. Ramoa, G. M. Barra, R. V. Oliveira, M. G. de Oliveira, M. Cossa and B. G. Soares, Polym. Int., 2013, 62(10), 1477-1484.

[59] M. R. Loos, J. Yang, D. L. Feke, I. Manas-Zloczower, S. Unal and U. Younes, Compos. Part B, 2013, 44(1), 740-744.

[60] P. C. Ma, S. Y. Mo, B. Z. Tang and J. K. Kim, Carbon, 2010, 48 (6), 1824-1834.

[61] S. Y. Yang, C. C. M.Ma, C. C. Teng, Y. W. Huang, S. H. Liao, Y. L. Huang, H. W. Tien, T. M. Lee and K. C. Chiou, Carbon, 2010, 48(3), 592-603.

[62] J. Cha, S. Jin, J. H. Shim, C. S. Park, H. J. Ryu and S. H. Hong, Mater. Des., 2016, 95, 1-8.
[63] K. T. Lau, M. Lu, C. K. Lam, H. Y. Cheung, F. L. Sheng and H. L. Li, Compos. Sci. Technol., 2005, 65(5), 719-725.

[64] Z. Zhao, W. C. Liao, N. Bhagavatula, L. J. Lee and J. M. Castro, Polym. Compos., 2016, 37(2), 435-445.

[65] D.Ensminger,Ultrasonics:fundamentals, technology, applications, Second ed. New York: Marcel Dekker, 1988.

[66] M. G. Villarreal, R. Mulyana, J. Castro and M. Cabrera-Rios, J. Polym. Eng., 2011, 31(5), 397-407.

[67] M. Chapartegui, J. Barcena, X. Irastorza, C. Elizetxea, M. Fernandez and A. Santamaria, Compos. Sci. Technol., 2012, 72 (4), 489-497.

[68] B. Ashrafi, J. Guan, V. Mirjalili, P. Hubert, B. Simard and A. Johnston, Compos. Part A, 2010, 41(9), 1184-1191.

[69] J. Chen, Y. Chen, H. Li, S. Lai and J. Jow, Ultrason Sonochem, 2010, 17(1), 66-71.

[70] W. Bauhofer and J. Z. Kovacs, Compos. Sci. Technol., 2009, 69 (10), 1486-1498.

[71] N. Zhang, F. Yang, D. Guerra, C. Shen, J. Castro and L. J. Lee, J. Appl. Polym. Sci., 2013, 129(4), 1875-1881.

[72] Z. Wu, S. Gao, L. Chen, D. Jiang, Q. Shao, B. Zhang, Z. Zhai, C. Wang, M. Zhao, Y. Ma and X. Zhang, Macromol. Chem. Phys., 2017, 218(23), 1700357.

[73] U. S. Tewari, A. P. Harsha, A. M. Hager and K. Friedrich, Compos. Sci. Technol., 2003, 63(3), 549-557.

[74] Z. Liu, G. Bai, Y. Huang, Y. Ma, F. Du, F. Li, T. Guo and Y. Chen, Carbon, 2007, 45(4), 821-827.

[75] Z. Chen, C. Xu, C. Ma, W. Ren and H. M. Cheng, Adv. Mater., 2013, 25(9), 1296-1300.

[76] D. Markham, Mater. Des., 1999, 21(1), 45-50.

[77] T. K. Gupta, B. P. Singh, S. Teotia, V Katyal., S. R. Dhakate and R. B. Mathur, J. Polym. Res., 2013, 20(6), 169.

[78] Z. Liu, G. Bai, Y. Huang, F. Li, Y. Ma, T. Guo, X. He, X. Lin, H. Gao and Y. Chen, J. Phys. Chem. C, 2007, 111(37), 1369613700 .

[79] D. J. Lipomi, M. Vosgueritchian, B. C. Tee, S. L. Hellstrom, J. A. Lee, C. H. Fox and Z. Bao, Nat. Nanotechnol., 2011, 6(12), 788-792.

[80] J. W. Zha, W. Huang, S. J. Wang, D. L. Zhang, R. K. Li and Z. M. Dang, Adv. Mater. Inter., 2016, 3(1), 1500418.

[81] P. Verma, P. Saini, R. S. Malik and V. Choudhary, Carbon, 2015, 89, 308-317.

[82] D. Zhang, J. Tong, B. Xia and Q. Xue, Sensor. Actuat. B, 2014, 203, 263-270.

[83] M. Amjadi, Y. J. Yoon and I. Park, Nanotechnology, 2015, 26 (37), 375501.

[84] G. Cai, J. Wang, K. Qian, J. Chen, S. Li and P. S. Lee, Adv. Sci., 2017, 4(2), 1600190.

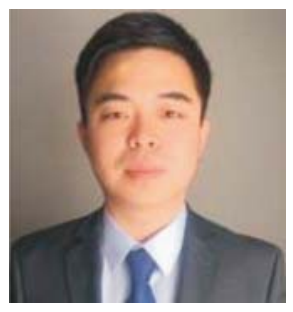

Dr. Dan Zhang is a Postdoc researcher in the Department of Integrated Systems Engineering at The Ohio State University, Columbus, $\mathrm{OH}$. His research interests include advanced manufacturing and applications of carbon nanomaterial reinforced polymer nanocomposites, 
polymer injection molding and extrusion. His research work can be applicable towards automotive, aerospace and sensor industries.

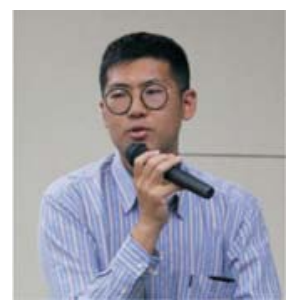

Dr. Jingyao Sun is an Associate Professor in the College of Mechanical and Electrical Engineering at Beijing University of Chemical Technology. Dr Sun's research interests focus on advanced polymer manufacturing and processing technology and equipment for polymer-based functional composites.

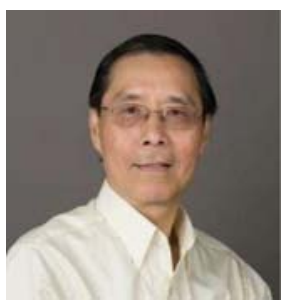

Dr. L. James Lee is the Emeritus Helen C. Kurtz Professor of Chemical and Biomolecular Engineering at The Ohio State University (OSU). His research interests include polymer-based micro/ nanotechnologies, polymer composites, and materials processing. He founded and led the NSF Center for Advanced Polymer and Composite Engineering (CAPCE), NSF Nanoscale Science and Engineering Center for Affordable Nanoengineering of Polymer Biomedical Devices (CANPBD), and Ohio Center for Multifunctional Polymer Nanomaterials and Devices (CMPND) at OSU. He has more than 400 refereed journal publications, 30 patents and invention disclosures, and 15 book chapters. He is a fellow of the Society of Plastic
Engineers. He received the 2008 Malcolm E. Pruitt Award from Council of Chemical Research, 2010 International Award from the Society of Plastic Engineers, and 2016 Lifetime Achievement Award, Society of Advanced Molding Technology.

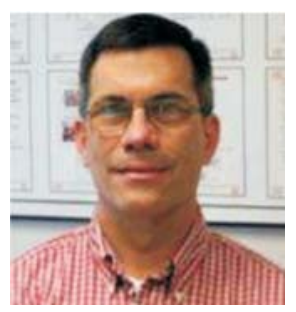

Dr. Jose M. Castro is a Professor in the Department of Integrated Systems Engineering, and director of the Center for Advanced Polymers and Composites Engineering at The Ohio State University. His research interests include polymer processing, and composites manufacturing modeling and optimization. He has 20 years academic R\&D experience and 17 years industry experience, with 100+ referred journal publications. Before joining The Ohio State University in 1998, he worked at the Gen Corp corporate technology center for 12 years in automotive composites where he ended up as Chief Technologist. After GenCorp he worked for three years as Manager of the New Process technology group in Allied Signal Electronic Materials. He is a fellow of the Society of Plastics Engineers and the Institute of Physics.

Publisher's Note: Engineered Science Publisher remains neutral with regard to jurisdictional claims in published maps and institutional affiliations. 